HIAS-E-95

\title{
A New Impetus for Endogenous Growth: R\&D Offshoring via Virtual Labor Mobility
}

\author{
Noritsugu Nakanishi ${ }^{(a)}$ and Ngo Van Long ${ }^{(b),(c)}$ \\ (a) Kobe University, Rokkodai-cho 2-1, Nada-ku, Kobe 657-8501, Japan \\ (b) McGill University, Montreal, Canada \\ (c) Hitotsubashi Institute for Advanced Study, Hitotsubashi University
}

February, 2020

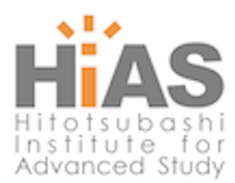

Hitotsubashi Institute for Advanced Study, Hitotsubashi University 2-1, Naka, Kunitachi, Tokyo 186-8601, Japan

tel:+81 425808604 http://hias.hit-u.ac.jp/

HIAS discussion papers can be downloaded without charge from: http://hdl.handle.net/10086/27202

https://ideas.repec.org/s/hit/hiasdp.html

All rights reserved. 


\title{
A New Impetus for Endogenous Growth: R\&D Offshoring via Virtual Labor Mobility
}

\author{
Noritsugu NAKANISHI and Ngo Van LONG
}

\begin{abstract}
We develop a simple North-South model of quality ladders to show that the virtual mobility of labor across time zones, facilitated by the advance in communication technology, can raise the endogenous growth rate of the world economy. The unique balanced growth rate is increasing in the endowments of skilled labor in both countries and decreasing in the rate of impatience. Moreover, we find that partial R\&D offshoring to the South has initially a negative effect on the level of skilled wages in the North, but this is compensated for by its positive effect on the growth rate in both North and South.
\end{abstract}

JEL-Classification: F43, O41

Keywords: R\&D offshoring, Virtual labor mobility, Time zone difference, Endogenous growth, North-South trade

* Nakanishi: Kobe University, Rokkodai-

cho 2-1, Nada-ku, Kobe 657-8501, Japan. Email: nakanishi@econ.kobe-u.ac.jp. Phone: +81-78-803-6837 (Office direct).

†Long: McGill University,Montreal, Canada;

and Hitotsubashi Institute for Advanced Study, Hitotsubashi University. Email: ngo.long@mcgill.ca. 


\section{Data Availability Statement}

Data sharing is not applicable.

\section{Acknowledgement}

Part of this paper was written when Nakanishi was visiting McGill University and CIRANO. Nakanishi is grateful to the hospitality of both institutions. Nakanishi also acknowledges the financial support of the Japan Society for the Promotion of Science: Grant-in-Aid for Scientific Research (A), No.16H02016. 


\section{Introduction}

The offshoring of tasks to low-wage economies has generated much debate. On one hand, many economists have argued that, from a long run perspective, free trade in goods and services (tasks) is potentially welfare-enhancing. They point to the well-established proposition that under ideal conditions the gainers from free trade can compensate the losers and remain better off. On the other hand, other economists have reminded us two inescapable facts of life: (i) there are significant short-run adjustment $\operatorname{costs},{ }^{1}$ and (ii) in reality, losers are never fully compensated (Autor, Dorn, and Hanson, 2013). ${ }^{2}$ Several influential authors have suggested that offshoring is probably one of the significant factors that have contributed to job polarisation, falling wages and declining employment opportunities in developed economies (Krugman, 2008; Autor, Dorn, and Hanson, 2015; Acemoglu, Autor, Dorn, and Hanson, 2015).

While the bulk of offshoring occurs in the manufacturing sector, there is a growing trend of offshoring of tasks, which has been made possible by drastic improvements in the information and communication technology (ICT). For example, thanks to ICT, several hundred US hospitals have used overseas tele-radiology services (Wachter, 2006). When an emergency CT scan is taken at midnight in a hospital located in New York, it is 10:30 a.m. in

\footnotetext{
${ }^{1}$ Adam Smith was well aware of these costs. In the Wealth of Nations, referring to adjustment costs that accompany a sudden influx of imports, he wrote that "Humanity may in this case require that freedom of trade should be restored only by slow gradations and with a good deal of reserve and circumspection. Were those duties (i.e., tariffs) and prohibitions (i.e., quotas) taken away all at once, cheaper foreign goods of the same kind might be poured so fast into the home market, as to deprive all at once many thousands of our people of their ordinary employment and means of subsistence."

${ }^{2}$ For the US, the medium-run adjustment costs have recently been found to be more substantial than many economists had thought. Using US local labor market data covering the period 1990-2007, Autor, Dorn, and Hanson (2013, p.2159) found adverse distributional consequences and significant medium-run efficiency losses associated with adjustment to increased imports from China. As reported in the New York Times (17 May 2015), Professor Gordon Hanson admitted that "I think what we have learned is that the US labor markets aren't as flexible and self-correcting as I think we had presumed. The uneasiness I have about the way we've handled globalization is not so much about globalization itself. It's that if we don't have the right safety net, you're going to impose an enormous amount of hardship" (quoted by Binyamin Appelbaum in his NYT article, "Perils of Globalization When Factories Close and Towns Struggle," May 17, 2015).
} 
Bangalore, India, where radiologists employed by companies such as Teleradiology Solutions and NH Teleradiology 24/7 do the reading and report their findings back to the US hospital, with an average turn around of one hour. This stark example illustrates the fact that, where the virtual labor mobility is available, time zone differences among countries come into play as a new driving force for international trade in services. Other examples include software industry located in the US and India (Cairncross, 1997), and a semi-conductor chip manufacturer that keeps 24-hour chip design systems by locating design teams separately in the US, India and Europe (Brown and Linden, 2009). In this context, many people were struck by the sound of an alarm bell: in a well cited paper, Blinder (2006) argued that the offshoring of service sector jobs is likely to become a major concern in the decades to come, thanks to the advance in ICT. These services range from computer programming and chip designs to legal services and medical tasks such as radiology. According to an estimate by Blinder (2006), the number of US jobs that are potentially offshorable is in the range of 42 to 56 million, of which around 28-40 million are in the service sector. In a follow-up paper, Blinder (2009) stresses that since ICT keeps getting both better and cheaper, the scope for offshoring will increase inexorably, and wages of skilled workers in the advanced industrialized economies (the North) will suffer a setback.

On the contrary, there has been some empirical evidence that R\&D offshoring have brought gains to offshoring countries. Indeed, some empirical studies have pointed out some interesting features in the globalization of the $\mathrm{R} \& \mathrm{D}$ activities, which provide us with a fresh perspective for $\mathrm{R} \& \mathrm{D}$ offshoring that is quite different from Blinder $(2006,2009)$ 's anxieties about negative impacts of offshoring. Branstetter, Glennon, and Jensen (2018) have reported the transformation of landscape of global $R \& D$ expenditure by US-based multinational enterprises: (i) the total amount of the global R\&D expenditure from 1999 to 2014 has increased at an average annual rate of 5.6\%, much faster than the growth rate in US multinational employment of $2.1 \%$; (ii) the share of traditional destinations of the US foreign R\&D, such as the UK, Germany, Japan, France, and Canada, has declined from 74\% in 1989 down to $43 \%$ in 2014, whereas the share of emerging countries such as China, India, 
and Israel has grown rapidly by 2014 - the emergence of new R\&D hubs; (iii) R\&D offshoring is particularly important in ICT- and/or software-intensive countries and it is carried out by ICT- and/or software-intensive firms. Paying special attention both to the different modes of governance and to two types of innovation outcomes, Nieto and Rodriguez (2011) have shown that there is a positive and significant correlation between $R \& D$ offshoring and innovation performance. Similarly, Bertrand and Mol (2013) have found a positive and significant innovative effect of $R \& D$ offshore outsourcing, which is greater than that of R\&D domestic outsourcing, and they have argued that the key to innovation is heterogeneity of knowledge inputs that is made available to firms by the R\&D offshore outsourcing.

In a recent paper, Rodriguez and Nieto (2016) investigated the roles of $R \& D$ offshoring in the sales growth of small- and medium-sized enterprises (SMEs) and found a positive significant correlation between R\&D offshoring and firm growth. In a related study D'Agostino, Laursen, and Santangelo (2013) examined the impact of R\&D offshoring from advanced OECD countries/regions to emerging economies such as Brazil, Russia, India, China, Singapore, and Taiwan (BRICST) on the home knowledge production. They found that "regions that both offshore R\&D in medium/low technology-intensive sectors to BRICST and carry out above median level $\mathrm{R} \& \mathrm{D}$ at home, produce more knowledge than regions that either only offshore $R \& D$ in medium/low technology-intensive sectors to BRICST, or only conduct above median R\&D at home" (p.166). Similarly, conducting an empirical analysis on R\&D offshoring and the productivity growth of European regions, Castellani and Pieri (2013) found that "offshoring regions exhibit higher growth both in value added and employment than the non offshoring ones, but the growth in output is larger than the one of employment, thus determining positive productivity effects" (p.1588).

Motivated by both Blinder's concerns and the apparently more positive empirical evidence, in this paper we formalize a theoretical model of endogenous growth driven by partial offshoring of R\&D from North to South. A key ingredient of the model is the role of time zone difference, which makes a Northern firm's R\&D workers in North and in South complementary rather 
than substitute factors of production. Our main finding is that even though the partial offshoring of $R \& D$ tasks to South will have a (short-run) negative effect on the skilled wage in North, it will raise the rate of innovation and consequently boost the growth rate of Northern skilled workers' wage. The mechanism behind our model is that with the improved access to virtual skilled researchers from different time zones, especially from countries with lower wages, Northern firms will have incentives to give a greater push to their R\&D activities, even though R\&D successes are random.

There are two distinctive features of $R \& D$ that our model takes into account. One is that $R \& D$ is a cumulative process: the exchange and refinement of ideas come in consecutive steps. A project is completed only after a sequence of efforts. This feature of $R \& D$ renders it very sensitive to the ease with which researchers can interact with each other via communications networks. The other is that the fruit of $R \& D$ is uncertain by nature: even if we complete all the scheduled steps of an $R \& D$ project, we may fail to obtain the desired results. A firm's research department, which hires researchers, must take account of the uncertainty pertaining to $R \& D$ when it decides if a research project should be carried out.

To examine the effects of R\&D outsourcing over different time zones, we construct a variant of the Schumpeterian endogenous growth model developed by Aghion and Howitt (1992, 2009); see also Gersbach et al. (2013). We show that the partial offshoring of R\&D to the South will increase the growth rate of the North, but decreases the Northern skilled wages temporarily. The skilled workers (i.e., researchers or scientists) in the North will suffer from a sudden decrease in their income in the short run, but ultimately they will gain from a higher growth rate of their wages, in the long run.

The plan of our paper is as follows. A brief review of the related literature is presented in the next section. In Section 3, we develop a North-South model where Northern firms engage in R\&D activities to improve the quality of their intermediate inputs. In Section 4, we elaborate on how R\&D decisions are made in a stochastic environment. In Section 5, we consider a situation where no virtual skilled labor though communications network from South is available to the Northern R\&D firms, which we call "com- 
munications autarky." We show how the market for skilled labor is cleared and how the skilled wage rate and the rate of growth are determined along a balanced growth path in communications autarky. Section 6 considers a situation where the advancement of communication technology enables Northern R\&D firms to offshore their R\&D activities to South located in a different time zone, which we call "communications liberalization." We show how the communications liberalization leads to a short-term fall in the wages of Northern skilled workers, but an increase in the long-run growth rate of their wages. In Section 7, by taking account of full general equilibrium conditions, we show how the relative price of the final agriculture good in terms of the final manufacturing good (i.e., the terms-of-trade of South) and the national incomes of the countries are determined. Section 8 discusses the welfare implications of our findings and points to possible extensions of the model. Section 9 concludes.

\section{Related Literature}

Our paper is built on recent works in two streams of literature: (a) the identification of various channels through which time zone difference constitutes an important source of gain from trade, and (b) the analytics of trade in tasks and task offshoring.

Parallel to the advance of communication technology is the striking emergence of a series of insightful papers on the economics of time zones. Marjit (2007) was the first to prove that the time zone difference is a new independent source of comparative advantage. He considered a Ricardian model in which the production process of the time-zone-related good is vertically divided into two consecutive stages, each of which takes one normal working day. If a firm performs the production in its home country by employing only local workers, it takes two working days to complete producing one unit of the good because people normally work only in the daytime. ${ }^{3}$ In contrast, if a firm performs the first stage in the daytime of the home country and outsources the second stage via the communications networks to foreign

\footnotetext{
${ }^{3}$ For simplicity, we assume away the night-shift working.
} 
workers residing in a country located in the opposite time zone, the firm can get the finalized good one-day earlier than when the virtual labor mobility is not available. Without the virtual labor mobility, the consecutive production process is interrupted by the resting time every night and, therefore, the completion is delayed; on the other hand, with the virtual labor mobility, the production process can be made continuous and the completion time will be rendered shorter. Because of the existence of time discounting, the shorter production time enables the firm to obtain a higher profit. This continuity effect can be a cause of comparative advantage.

Focusing on the roles of night-shift working, Matsuoka and Fukushima (2010) pointed out another cause of comparative advantage related to the time zone difference. They assumed that the production process is vertically divided into two consecutive stages and that, unlike Marjit (2007), these stages must be performed continuously without any interruption. If a firm wants to continue the production during the night by hiring local workers in the home country, the firm has to pay a nighttime premium to the home workers in addition to the normal daytime wage rate; in contrast, if the firm can hire (indirectly through the communications networks) foreign workers in a country located in the opposite time zone during the nighttime in the home country (the foreign workers are in their daytime), the firm can save the nighttime premium payment because the foreign workers do the jobs in their own daytime. This cost-reduction effect can be another cause of comparative advantage, too.

As clearly shown by Marjit (2007), Matsuoka and Fukushima (2010) and others, ${ }^{4}$ both the continuity and cost-reduction effects of the virtual labor mobility improve the static efficiency of the production of time-zone-related goods. In view of this, one might think it natural that these effects also contribute to enhance the dynamic efficiency of the economy and to increase the economic growth rate. So far, however, only a few studies have dealt with the growth effects of time-zone-related trade in services and/or virtual labor mobility. Kikuchi and Marjit (2011) considered a simple two-country AK

\footnotetext{
${ }^{4}$ For other contributions concerning the time zone difference and comparative advantage, see Kikuchi $(2006,2009)$ and Kikuchi and Iwasa (2010).
} 
growth model that incorporates intermediate business services, which can be traded across different time zones. They showed that a reduction of the transaction cost of trade in services due to the advancement of the communications networks increases the endogenous growth rates of both countries. Marjit and Mandal (2017) extended the Kikuchi-Marjit model to an AK-type optimal endogenous growth model. They showed that the liberalization of trade in services can raise not only the level of the GDP of the country but also the growth rate. They also examined the labor market implications of the liberalization of trade in services across different time zones. ${ }^{5}$ The key factor that enhances growth in the Kikuchi-Marjit and Marjit-Mandal models is the expanded availability of the intermediate business services, which raises the marginal productivity of capital and, thereby, increases the growth rate. Their models, however, do not take account of R\&D activities. Needless to say, R\&D is one of the most important and vital driving forces of the economic growth. In this paper, we will focus on the roles of $R \& D$, in particular, on how the offshoring of R\&D through the communications networks taking advantage of time zone differences affects the growth rate. ${ }^{6}$

The recent literature on task offshoring receives a great push from the authoritative work of Grossman and Rossi-Hansberg (2008) (G\&RH for short). These authors were the first to identify three effects of offshoring: the productivity effect, the relative-price (terms-of-trade: TOT) effect, and the laborsupply effect. In G\&RH's main model, fragmentation is modelled as a decline in the cost of trading a continuum of unskilled tasks. This leads to a positive productivity effect that increases the wage of North's unskilled workers, and a positive TOT effect for North. In a variant specification, G\&RH suppose that skilled tasks can also be offshored. In this case, offshoring can lead to a deterioration in North's TOT. Although we also find these effects, the fea-

\footnotetext{
${ }^{5}$ In static settings, both Kikuchi and Long (2011) and Nakanishi and Long (2015) have examined the implications of trade in services across different time zone on the income distribution. The former is based on the standard Heckscher-Ohlin-Samuelson model; the latter on the Specific-Factors model.

${ }^{6}$ Within the framework of endogenous growth model, Davis and Hashimoto (2018) have developed a model in which firms are free to choose the locations of production activity and R\&D activity separately. They focused on the roles of occupational choice by (potential) workers and difference in the relative abundance of assets of the countries.
} 
tures of our model are considerably different from those of G\&RH's model. First, G\&RH assume perfectly competitive markets (p.1979), while we have a monopolistic competition sector. Second, they assume that "foreign and local tasks of a given type are perfect substitutes in production" (p.1982, footnote 12), while in our model the two R\&D teams (one in North and the other in South) are complements when both teams are employed (i.e., when part of an R\&D project is offshored). This is a distinctive feature of our model due to the time zone difference, which is absent in G\&RH. Third, in the first half of their paper, they used the "small country assumption," which they acknowledge (in their footnote 17) as a "somewhat artificial assumption," while we consider the case of two large economies in which the terms of trade is determined endogenously. Finally, G\&RH did not consider endogenous growth, while our emphasis is on the effect of partial offshoring of $\mathrm{R} \& \mathrm{D}$ on the rate of growth of the world economy.

Rodriguez-Clare (2010) (RC for short) compares short-run and long-run effect of offshoring. Similar to the current paper, RC considers a dynamic model in which technology levels are endogenous. Workers can choose to work in the production sector or to do research (p.230). In RC's model, both countries have a research sector, which is a different point from our model where research only occurs in North. Each country has a "stock of ideas," denoted by $T$, and it is assumed that the richer country has a higher stock of ideas per workers, $T / L$. In the short run, offshoring production reduces North's wage, but in the long run, as a larger fraction of North's workers become researchers, North can sustain a higher $T / L$, which translates into higher wage in North in the long run. RC concludes that "increased fragmentation could have negative effects for rich countries, but these effects dissipate in time, so that the long-run effects are always positive for the countries doing the offshoring" (p.231). In RC's model, by assumption, North does not offshore research to South. In our model, North is able to employ South's researchers via virtual labor mobility. While this is a form of R\&D offshoring, Southern researchers are complements rather than substitutes for Northern ones, because in our model, South's scientists working for North in South's daytime (i.e., in North's nightime), building on each other's previous 
steps.

In our model, there is no offshoring of production activities. If we extend the model to allow for offshoring of production, there would be additional considerations to take into account. For example, as argued by Naghavi and Ottaviano (2009), offshoring production activities may weaken the information feedback from production to R\&D. Some authors, such as Ernst (2006) and Macher and Mowery (2008), have voiced concerns about "actual offshoring" of R\&D activities. It should be noted that "actual offshoring" (in the sense of replacing Northern R\&D scientists with Southern ones) does not occur in our model, as they are complements, not substitutes.

In line with the empirical findings reported in Section 1, our model shows that partial offshoring of R\&D activities can enhance growth. Moreover, our approach highlights the importance role of time zone differences which turn foreign and domestic researchers into complementary factors rather than substitutes. We show how both North and South benefit from the endogenous growth generated by the increase in worldwide $R \& D$ activities.

\section{Model}

There are two countries, North and South. North is endowed with $L$ units of unskilled labor and $H$ units of skilled labor. We assume that North's unskilled labor can only be used as an input of a final manufacturing good. North is capable of producing a final manufacturing good (i.e., the North good) under a constant-returns-to-scale technology, using as inputs (i) unskilled labor and (ii) a continuum of intermediate inputs indexed by $z$, where $z$ belongs to the real interval $[0,1]$. Each unit of intermediate good $z$ is produced by a firm, also denoted by $z$, using one unit of skilled labor. Skilled labor can also be employed in the R\&D sector. The quantity of skilled workers employed in the production of intermediate goods (respectively, in the R\&D sector) in period $t$ is denoted by $H_{I, t}$ (respectively, $\left.H_{R, t}\right) .^{7}$ The full

\footnotetext{
${ }^{7}$ We assume a discrete-time dynamic model. Subscript " $t$ " attached to some variables indicates "period $t . "$
} 
employment condition for skilled labor is

$$
H_{I, t}+H_{R, t}=H
$$

As in Romer (1990), the final manufacturing good is produced under perfect competition, while the firms that produce intermediate goods operate under monopolistic competition and earn positive profits. Intermediate goods are not durable nor tradable goods. As for the formulation of R\&D decisions, we assume that the incumbent firm $z$ is the only one that conducts $R \& D$ activities for that input. ${ }^{8}$ We will explain later how the demands for skilled labor in the intermediate good production and in the $R \& D$ activities are determined.

South is endowed with $L^{*}$ units of unskilled labor and $H^{*}$ units of skilled labor. South specializes in a traditional agriculture good (i.e., the South good), which is produced under a Ricardian technology by using only unskilled labor as input; the labor input-coefficient is assumed to be one. Since, in the absence of R\&D offshoring from North, there is no job for the Southern skilled workers, South's skilled labor can only work as unskilled labor and earn South's unskilled wage. Thus, in the communications autarchy scenario, the whole labor force in South, $L^{*}+H^{*}$, is employed as unskilled labor in the agricultural sector and, accordingly, the wage rates received by two different types of labor in South are equalized. In this scenario, South's output of the agriculture good, denoted by $y_{S}$, becomes

$$
y_{S}=L^{*}+H^{*}
$$

South exports some of its agricultural output to North and imports North's final manufacturing good. By assumption, North is not capable of producing the agricultural good, and South is not capable of producing the

\footnotetext{
${ }^{8}$ There is another possible formulation of $\mathrm{R} \& \mathrm{D}$ decisions: in each intermediate input sector $z$, there is a pool of potential innovators who are attempting to improve the quality of $z$; if an innovator succeeds in the quality improvement, she captures the current market for the very intermediate input $z$ and becomes a monopoly. Because this alternative formulation of $\mathrm{R} \& \mathrm{D}$ decision has some theoretical difficulties, we adopt the formulation described in the text.
} 
final manufacturing good nor the intermediate good. All firms (i.e., manufacturing firms, agriculture firms, intermediate-good/R\&D firms) do not move across countries.

\subsection{Household Sector}

Preferences of households/consumers are the same in North and South. We assume that consumers are infinitely-lived individuals. Without loss of generality, we assume that in each country, the population size is equal to unity. Because the same argument equally applies to both countries, we omit the superscript ( $N$ or $S$ ) that indicates the identity of a country in this subsection.

In period $t$, any individual who consumes $c_{S, t}$ units of the agriculture good and $c_{N, t}$ units of the final manufacturing good derives the (temporal) utility from the following Cobb-Douglas function:

$$
U\left(c_{S, t}, c_{N, t}\right)=\delta \ln \left[c_{S, t}\right]+(1-\delta) \ln \left[c_{N, t}\right]
$$

where $0<\delta<1$.

In principle, in any period, a consumer can consume more or less than her current income. Let $E_{t}$ be the consumption expenditure in period $t$ by the representative consumer. In any period $t$, given her chosen consumption expenditure level $E_{t}$, the consumer chooses the quantities of two consumption goods, $c_{S, t}$ and $c_{N, t}$, to maximize her utility function (Eq. (1)) subject to the (temporal) budget constraint:

$$
p_{t} c_{S, t}+c_{N, t}=E_{t}
$$

where $p_{t}$ is the price of agriculture good in terms of the manufacturing good in period $t$. This yields the demand functions for the final consumption goods:

$$
\begin{aligned}
c_{S, t} & =\frac{\delta E_{t}}{p_{t}}, \\
c_{N, t} & =(1-\delta) E_{t} .
\end{aligned}
$$


Substituting the above results back into Eq. (1), we obtain the (temporal) indirect utility function:

$$
V\left(E_{t}, p_{t}\right) \equiv \ln \left[E_{t}\right]-(1-\delta) \ln \left[p_{t}\right]+\kappa,
$$

where $\kappa \equiv \delta \ln \delta+(1-\delta) \ln (1-\delta)$ is a constant.

To determine the consumer's optimal time path of expenditure $E_{t}$ for $t=0,1,2, \ldots, \infty$, we posit that the consumer solves her intertemporal optimization problem:

$$
\max _{\left\{E_{t}\right\}} \mathcal{E}_{0} \sum_{t=0}^{\infty} \frac{1}{(1+\rho)^{t}} V\left(E_{t}, p_{t}\right),
$$

where $\rho$ is the consumer's degree of impatience (i.e., the utility discount rate) and $\mathcal{E}_{0}$ is the expectation operator. The intertemporal optimization is subject to the intertemporal budget constraint that the present value of the expenditure stream (i.e., $E_{t}$ for $t=0,1,2, \ldots$ ) be equal to the present value of the income stream (i.e., $I_{t}$ for $t=0,1,2, \ldots$ ):

$$
\mathcal{E}_{0} \sum_{t=0}^{\infty} \prod_{\tau=0}^{t}\left(1+r_{\tau}\right)^{-1}\left[E_{t}-I_{t}\right]=0
$$

where $\prod_{\tau=0}^{t}\left(1+r_{\tau}\right)^{-1}$ is the discount factor and $r_{\tau}$ is the equilibrium interest rate in period $\tau$.

In later sections, we will focus on balanced growth paths. Along a balanced growth path, the rate of interest becomes a constant, $r$, which is endogenously determined via the well-known Keynes-Ramsey equation: ${ }^{9}$

$$
r=\rho+\frac{g_{E}}{\sigma}
$$

where $g_{E}$ is the rate of growth of consumption expenditure and $\sigma$ is the elasticity of intertemporal substitution. In balanced growth, $g_{E}$ is equal to the growth rate of income. In fact we will show that, in our model, the growth rate of national income is the same for both countries. Further, it should be noted that, we have $\sigma=1$ because of the logarithmic indirect utility function derived in Eq. (5).

\footnotetext{
${ }^{9}$ For the derivation of the Keynes-Ramsey equation, see Appendix A.
} 
Concerning the financing of $R \& D$ expenditure by intermediate good firms, we note that in our model, the firm's expenditure on R\&D may be higher or lower than its flow of revenue from sales net of production cost. To finance R\&D, the firm can issue bonds (I.O.U.'s) to consumers in North. This does not create any difficulty to our analysis, because in a model with identical consumers, all consumers in North know that the firm's debt is not part of their net wealth; even bonds issued by North's government, if any, are not considered by the identical consumers in North as part of their net wealth, as Barro (1974) pointed out in his famous paper on Ricardian equivalence.

\subsection{The Manufacturing Good Firms}

The manufacturing good (the North good) is produced by perfectly competitive firms, under the production function

$$
y_{N, t}=L_{u, t}^{1-\alpha} \int_{0}^{1}\left[A_{t}(z)\right]^{1-\alpha}\left[x_{t}(z)\right]^{\alpha} \mathrm{d} z .
$$

where $L_{u, t}$ is unskilled labor input, $x_{t}(z)$ is the quantity of intermediate good $z$, and $A_{t}(z)$ is the quality of intermediate input $z$ in period $t$. We assume that the manufacturing good is the numéraire and its price is normalized to unity. Let $w_{u, t}$ denote the unskilled wage rate and $q_{t}(z)$ the price of intermediate good $z$ in period $t$. The representative manufacturing firm takes $w_{u, t}$ and $q_{t}(z)$ as given, for all $z \in[0,1]$. Its profit maximization problem is

$$
\max L_{u, t}^{1-\alpha} \int_{0}^{1}\left[A_{t}(z)\right]^{1-\alpha}\left[x_{t}(z)\right]^{\alpha} \mathrm{d} z-\int_{0}^{1} q_{t}(z) x_{t}(z) \mathrm{d} z-w_{u, t} L_{u, t}
$$

The first-order conditions are such that each factor is chosen at a level that equates its marginal product to its factor price:

$$
\begin{aligned}
w_{u, t} & =(1-\alpha) L_{u, t}^{-\alpha} \int_{0}^{1}\left[A_{t}(z)\right]^{1-\alpha}\left[x_{t}(z)\right]^{\alpha} \mathrm{d} z=(1-\alpha) \frac{y_{N, t}}{L_{u, t}} \\
q_{t}(z) & =\alpha\left[A_{t}(z)\right]^{1-\alpha}\left[x_{t}(z)\right]^{\alpha-1} L_{u}^{1-\alpha} .
\end{aligned}
$$

The above system of equations implicitly defines the demand for unskilled labor, denoted by $L_{u, t}^{D}$, and that for intermediate inputs. 
We assume that the economy's available unskilled labor is supplied inelastically and equal to $L>0$. Then, the market equilibrium condition for unskilled labor in North becomes

$$
L_{u, t}^{D}=L
$$

Accordingly, Eqs. (8) and (9) can be rewritten as follows:

$$
\begin{aligned}
w_{u, t} & =(1-\alpha) \frac{y_{N, t}}{L}, \\
q_{t}(z) & =\alpha\left[A_{t}(z) L\right]^{1-\alpha}\left[x_{t}(z)\right]^{\alpha-1} .
\end{aligned}
$$

The second condition gives the demand function for intermediate input $z$ :

$$
x_{t}(z)=\left[\frac{\alpha}{q_{t}(z)}\right]^{\frac{1}{1-\alpha}} A_{t}(z) L .
$$

Notice that $x_{i}(t)$ is increasing in $L$, as expected. Indeed, the size of the unskilled labor force, $L$, is a good indicator of the size of the manufacturing sector. The larger is manufacturing sector, the greater is the demand for intermediate inputs.

\subsection{The Intermediate Good Firms}

Each intermediate good firm is a monopoly in each sector; one unit of intermediate input production requires one unit of skilled labor. Let $w_{t}$ denote the skilled wage rate in period $t$. Each firm sets its price $q_{t}(z)$ to maximize its profit $\pi_{t}(z) \equiv\left[q_{t}(z)-w_{t}\right] x_{t}(z)$ subject to the intermediate good demand (Eq. (10)). The solution yields the constant mark-up pricing rule:

$$
q_{t}(z)=\frac{w_{t}}{\alpha} .
$$

This rule implies that in equilibrium, the demand for each intermediate input is decreasing in the skilled wage rate, and increasing in its quality level:

$$
x_{t}(z)=\left[\frac{\alpha^{2}}{w_{t}}\right]^{\frac{1}{1-\alpha}} A_{t}(z) L .
$$

Then, the maximized profit of the intermediate good firm is

$$
\pi_{t}(z) \equiv \theta\left(w_{t}\right)^{\frac{-\alpha}{1-\alpha}} A_{t}(z) L
$$


where $\theta \equiv(1-\alpha) \alpha^{\frac{1+\alpha}{1-\alpha}}$ is a positive constant. Note that both the profit maximizing output of the intermediate good and the maximized profit are linear in the quality parameter $A_{t}(z)$.

\section{Research and Development}

We model R\&D as follows. We assume that the incumbent intermediategood firm $z$ is the only one that conducts $R \& D$ activities for that input. Its research department employs researchers to carry out a research project. A project needs to be implemented in a sequence of steps. The second step cannot begin unless the first step has been completed, and so on. Each step takes 12 consecutive hours of a researcher. For simplicity, we assume that a research team consists of only one researcher. (If the research department employs two researchers on the same day to work on the same project, their total research output is not greater than that of a single researcher.)

Researchers work only during their local daytime. If a research firm in North relies only on Northern researchers, then at the end of the year, its research project will have completed 365 steps. On the other hand, if the firm uses both Northern and Southern researchers (located in the opposite time zone) then at the end of the year, its research project will have completed 730 steps. We assume that one period of time consists of 365 days (i.e., one period is equal to one year) and that a single project requires 365 steps and the result of one project can be obtained only after finishing the 365th step. Therefore, a firm can complete at most one project in one period if it uses only Northern researchers, while it can complete up to two projects in one period if it can use both Northern and Southern researchers.

\subsection{R\&D Indicator}

Let $R$ be the domestic R\&D indicator; similarly, $R^{*}$ be the foreign-outsourcing R\&D indicator. We assume that $R$ and $R^{*}$ are binary variables, not continuous variables:

$$
R, R^{*} \in\{0,1\}
$$


One unit of research project is divided into 365 steps; each step takes one regular working day (12 hours). The $(s+1)$-th step cannot begin unless the $s$ th step has been completed; and the result can be obtained only after finishing the 365th step. Then, without partial offshoring of R\&D, each research department can accomplish at most one research project per year. When partial offshoring of $\mathrm{R} \& \mathrm{D}$ is possible, in contrast, a research department can undertake two research projects in the following manner: the 1st step of one project is carried out in the home country in the first day of a year; the 2nd step is outsourced to a foreign country located in the opposite time zone in the first day (but, the nighttime in home); the 3rd step is carried out in the home country in the second day, the 4 th step is outsourced to the foreign country in the second day (the nighttime in home) and so on. In this way, the length of time for completion of one project is compressed to half a year. Then, by using the second half of a year, the research firm can undertake one more project.

\subsection{R\&D Productivity}

By conducting $R \& D$, each research department can increase the growth rate $g_{t}(z)$ of $A_{t}(z)$. The relation between $g_{t}(z)$ and the research indicators is represented by

$$
g_{t}(z)=\lambda\left[R+R^{*}\right], \quad R, R^{*} \in\{0,1\},
$$

where $\lambda \geq 0$ stands for the productivity of R\&D in terms of the size of quality innovation. Further, we assume that $\lambda$ is a stochastic variable that has a compact support $\left[\lambda_{L}, \lambda_{H}\right]$ where $0<\lambda_{L}<\lambda_{H}$. (More precisely, we should write $\lambda_{t, z}$ because the realized values of $\lambda$ differ across firms and across periods; however we omit these subscripts to lighten notation.) The distribution function $F$ of $\lambda$ must satisfy $F\left(\lambda_{L}\right)=0$ and $F\left(\lambda_{H}\right)=1$ and $F^{\prime}(\lambda)>0$ for $\lambda \in\left[\lambda_{L}, \lambda_{H}\right]$. For this to hold, we propose the following 
distribution $^{10}$

$$
F(\lambda) \equiv\left\{\begin{array}{ccc}
1+\frac{\beta}{\lambda_{H}}-\frac{\beta}{\lambda} & \text { if } \quad \lambda \in\left[\lambda_{L}, \lambda_{H}\right] \\
1 & \text { if } \quad \lambda>\lambda_{H} \\
0 & \text { if } \quad \lambda<\lambda_{L}
\end{array}\right.
$$

where $\beta \equiv \lambda_{H} \lambda_{L} /\left(\lambda_{H}-\lambda_{L}\right)$. Then, the density function $f$ becomes

$$
f(\lambda)=\left\{\begin{array}{lll}
\frac{\beta}{\lambda^{2}} & \text { if } & \lambda \in\left[\lambda_{L}, \lambda_{H}\right], \\
0 & \text { if } & \lambda \notin\left[\lambda_{L}, \lambda_{H}\right] .
\end{array}\right.
$$

The expected value of $\lambda$ is

$$
E(\lambda)=\int_{\lambda_{L}}^{\lambda_{H}} \lambda \cdot \frac{\beta}{\lambda^{2}} \mathrm{~d} \lambda=\beta \ln \left[\frac{\lambda_{H}}{\lambda_{L}}\right] .
$$

Taking account of the definition of growth rate, we can rewrite Eq. (13) as follows:

$$
A_{t+1}(z)-A_{t}(z)=\lambda\left[R+R^{*}\right] A_{t}(z)
$$

which means that an increment of the quality of intermediate good $z$ is proportional to the product of the skilled labor input $\left[R+R^{*}\right]$ and the current quality $A_{t}(z)$. This is reminiscent of what Rivera-Batiz and Romer (1991a) called the knowledge-driven specification of $\mathrm{R} \& \mathrm{D}$. In their model, the state of technology is represented by a closed interval of continuous range of intermediate goods with its upper bound being $A$, which also reflects the current knowledge level, and technological progress due to $\mathrm{R} \& \mathrm{D}$ is represented by the differential equation $\dot{A}=\delta H A$, where $H$ is the skilled labor input to R\&D and $\delta$ is a positive constant. The resemblance between the R\&D function in Rivera-Batiz and Romer (1991a) and that in our model is obvious. ${ }^{11}$

There is, however, a subtle but important difference between the R\&D function in Rivera-Batiz and Romer (1991a) and that in our model. In the

\footnotetext{
${ }^{10}$ This distribution is a modified version of the standard Pareto distribution, where $F(\lambda)=1-(B / \lambda)^{a}$ for $\lambda \geq B$ and $F(\lambda)=0$ for $\lambda<B$, where $B$ is a positive parameter.

${ }^{11}$ Rivera-Batiz and Romer (1991a) have also proposed an alternative specification of R\&D called the lab equipment specification, which depends on human capital, unskilled labor, and capital goods, but not on the current level of knowledge per se (i.e., $A$ ).
} 
former case, each skilled worker in $H$ can be considered a perfect substitute for other skilled workers in $H$. In our case, although the skilled workers in North and South enter the R\&D production function in the additive form, this does not mean that the Northern skilled workers $R$ and the Southern skilled workers $R^{*}$ are substitutes for each other. Because the Southern skilled workers are available to the Northern research firms only in the nighttime of North, they do not directly compete with the Northern skilled workers who are active only in the daytime of North. The Southern skilled workers are irreplaceable with the Northern skilled workers and vice versa. The Northern and Southern skilled workers are, in a sense, complements rather than substitutes.

\subsection{Expected profits from R\&D investment}

At the beginning of period $t$, each firm's research department draws its R\&D productivity $\lambda$ from $F$. After knowing $\lambda$, the firm makes a decision on R\&D. If firm $z$ decides to do R\&D, it can improve the quality of intermediate good $z$ according to the R\&D function, Eq. (13), and the realized $\lambda$. The next period's quality after this period's $\mathrm{R} \& \mathrm{D}$ is given by $A_{t+1}(z)=\left(1+g_{t}(z)\right) A_{t}(z) \equiv\left(1+\lambda\left[R+R^{*}\right]\right) A_{t}(z)$. For simplicity, we assume that the skilled-labor input coefficient for R\&D is equal to unity. Concerning the cost of offshoring, Grossman and Rossi-Hansberg (2008) argued that "[offshoring of tasks] is costly, because remote performance of a task limits the opportunities for monitoring and coordinating workers" (p.1978). Along the lines with their argument, we introduce a parameter that represents the communication cost between the head office in North and the R\&D workers in South. Then, the expected net returns from period t's R\&D investment becomes

$$
\theta\left(w_{t+1}\right)^{\frac{-\alpha}{1-\alpha}}\left(1+\lambda\left[R+R^{*}\right]\right) A_{t}(z) L-\left(1+r_{t}\right)\left(w_{t} R+\tau w_{t}^{*} R^{*}\right),
$$

where $r_{t}, w_{t}^{*}$, and $\tau \geq 1$ represent the interest rate, the foreign skilled wage rate, and the iceberg-type communication cost, respectively. ${ }^{12}$

\footnotetext{
${ }^{12}$ Formally, Grossman and Rossi-Hansberg (2008) assumed that $a_{L j} \beta t_{j}(i)$ units of foreign labor is required to perform task $i$ in producing a unit of good $j$ and that $\beta t_{j}(i) \geq 1$
} 
On the other hand, if the firm does not conduct R\&D, the quality of $z$ does not improve, i.e., $A_{t+1}(z)=A_{t}(z)$, and the profit in period $t+1$ is simply

$$
\theta\left(w_{t+1}\right)^{\frac{-\alpha}{1-\alpha}} A_{t}(z) L
$$

If the profit in Eq. (16) is greater than the profit in Eq. (17), the firm will carry out the R\&D project.

\subsection{R\&D under Communications Autarky in North}

Under communications autarky, firms cannot offshore R\&D. Therefore, we have $R^{*}=0$ a priori. The condition for domestic R\&D to be carried out (i.e., the condition for $R=1$ ) is that the profit in Eq. (16) is greater than the profit in Eq. (17). With appropriate arrangements, we have $R=1$ if and only if

$$
\lambda>\frac{\phi w_{t}\left(w_{t+1}\right)^{\frac{\alpha}{1-\alpha}}}{A_{t}(z) L}
$$

where $\phi \equiv\left(1+r_{t}\right) \theta^{-1}$. Although $\phi$ depends upon "period $t$ " via the rate of interest $r_{t}$, we omit an explicit indication of $t$ from $\phi$ for notational simplicity. Furthermore, for any sector $z$, let

$$
\widehat{\lambda}_{z, t} \equiv \frac{\phi w_{t}\left(w_{t+1}\right)^{\frac{\alpha}{1-\alpha}}}{A_{t}(z) L} .
$$

Then, the decision on R\&D by firm $z$ can be summarized by the following decision function $h$ :

$$
h\left(\lambda \mid \widehat{\lambda}_{z, t}\right) \equiv\left\{\begin{array}{lll}
1 & \text { if } & \lambda>\widehat{\lambda}_{z, t} \\
0 & \text { if } & \lambda \leq \widehat{\lambda}_{z, t}
\end{array}\right.
$$

As $\lambda$ is a stochastic variable drawn from the distribution function $F$, the probability for $R=1$ can be written as follows:

$$
\operatorname{Prob}[R=1]=\operatorname{Prob}\left[\lambda>\widehat{\lambda}_{z, t}\right]
$$

for all $i$ and $j$. Their $\beta t_{j}(i)$, in particular, their parameter $\beta$ and our $\tau$ play a similar role. To quote Grossman and Rossi-Hansberg (2008): "Reductions in this parameter represent improvements in communication and transportation technology that reduce proportionally the cost of offshoring all tasks performed by low skilled labor. With this parameterization, we can address an important and topical question, namely: how do improvements in the opportunities for offshoring affect the wages and well-being of different types of labor?" 


$$
\begin{aligned}
& =1-\operatorname{Prob}\left[\lambda \leq \widehat{\lambda}_{z, t}\right] \\
& =1-F\left(\widehat{\lambda}_{z, t}\right) .
\end{aligned}
$$

More specifically,

$$
\operatorname{Prob}[R=1]=1-F\left(\widehat{\lambda}_{z, t}\right)=\left\{\begin{array}{lll}
1 & \text { if } & \widehat{\lambda}_{z, t}<\lambda_{L}, \\
\frac{\beta}{\widehat{\lambda}_{z, t}}-\frac{\beta}{\lambda_{H}} & \text { if } & \widehat{\lambda}_{z, t} \in\left[\lambda_{L}, \lambda_{H}\right] \\
0 & \text { if } & \widehat{\lambda}_{z, t}>\lambda_{H} .
\end{array}\right.
$$

Note that this probability also gives the demand for domestic skilled labor in $\mathrm{R} \& \mathrm{D}$ from sector $z$.

\subsection{Skilled Labor Market in North}

Let $H$ be the domestic supply of the skilled workers. These skilled workers are either employed in the production of intermediate inputs, or hired as researchers. The skilled-labor demand for the production of intermediate goods, $H_{I, t}$, is represented by a function $D_{I}$ of $w_{t}$ :

$$
H_{I, t}=D_{I}\left(w_{t}\right) \equiv \int_{0}^{1}\left\{\left[\frac{\alpha^{2}}{w_{t}}\right]^{\frac{1}{1-\alpha}} A_{t}(z) L\right\} \mathrm{d} z \equiv \frac{\alpha^{\frac{2}{1-\alpha}} \int_{0}^{1} A_{t}(z) L \mathrm{~d} z}{\left(w_{t}\right)^{\frac{1}{1-\alpha}}}
$$

Concerning the demand for researchers, let us partition the set of firms into three subsets, denoted by $\Omega_{H, t}, \Omega_{M, t}$, and $\Omega_{L, t}$, where

$$
\begin{aligned}
& \Omega_{H, t} \equiv\left\{z \in[0,1] \mid A_{t}(z) L>\frac{\phi w_{t}\left(w_{t+1}\right)^{\frac{\alpha}{1-\alpha}}}{\lambda_{L}}\right\}, \\
& \Omega_{M, t} \equiv\left\{z \in[0,1] \mid \frac{\phi w_{t}\left(w_{t+1}\right)^{\frac{\alpha}{1-\alpha}}}{\lambda_{L}} \geq A_{t}(z) L \geq \frac{\phi w_{t}\left(w_{t+1}\right)^{\frac{\alpha}{1-\alpha}}}{\lambda_{H}}\right\}, \\
& \Omega_{L, t} \equiv\left\{z \in[0,1] \mid \frac{\phi w_{t}\left(w_{t+1}\right)^{\frac{\alpha}{1-\alpha}}}{\lambda_{H}}>A_{t}(z) L\right\} .
\end{aligned}
$$

Firms in the set $\Omega_{H, t}$ have very high $A_{t}(z)$ and therefore will do R\&D, regardless of the value of their random draw $\lambda$ (which we know is always in the set $\left.\left[\lambda_{L}, \lambda_{H}\right]\right)$. These firms will set $R=1$. Firms in the set $\Omega_{L, t}$ have 
very low $A_{t}(z)$ and will not do $\mathrm{R} \& \mathrm{D}$, regardless of the value of their random draw $\lambda$. Lastly, firms in the set $\Omega_{M, t}$ will do $\mathrm{R} \& \mathrm{D}$ with a positive probability $\beta / \widehat{\lambda}_{z, t}-\beta / \lambda_{H}$.

Without loss of generality, re-label firms so that each of $\Omega_{H, t}, \Omega_{M, t}$, and $\Omega_{L, t}$ is a connected subset of the unit interval $[0,1]$. Thus, the expected demand for researchers, $H_{R, t}$, is represented by a function $D_{R}$ of $w_{t}$ and $w_{t+1}$ :

$$
H_{R, t}=D_{R}\left(w_{t}, w_{t+1}\right) \equiv\left|\Omega_{H, t}\right|+\int_{\Omega_{M, t}}\left\{\frac{\beta A_{t}(z) L}{\phi w_{t}\left(w_{t+1}\right)^{\frac{\alpha}{1-\alpha}}}-\frac{\beta}{\lambda_{H}}\right\} \mathrm{d} z,
$$

where $\left|\Omega_{H, t}\right|$ denotes the length of the interval $\Omega_{H, t}$.

In what follows, for simplicity, we assume that the sets $\Omega_{H, t}$ and $\Omega_{L, t}$ are empty, implying that $\Omega_{M, t}=[0,1] .{ }^{13}$ This assumption would hold if no firm has a long sequence of highly favorable (or highly unfavorable) realizations of $\lambda$. Then

$$
\begin{aligned}
D_{R}\left(w_{t}, w_{t+1}\right) & \equiv 1-\int_{0}^{1} F\left(\frac{\phi w_{t}\left(w_{t+1}\right)^{\frac{\alpha}{1-\alpha}}}{A_{t}(z) L}\right) \mathrm{d} z \\
& =1-\int_{0}^{1}\left[1+\frac{\beta}{\lambda_{H}}\right] \mathrm{d} z+\int_{0}^{1} \frac{\beta A_{t}(z) L}{\phi w_{t}\left(w_{t+1}\right)^{\frac{\alpha}{1-\alpha}}} \mathrm{d} z \\
& =\frac{\beta \int_{0}^{1} A_{t}(z) L \mathrm{~d} z}{\phi w_{t}\left(w_{t+1}\right)^{\frac{\alpha}{1-\alpha}}}-\frac{\beta}{\lambda_{H}} .
\end{aligned}
$$

Clearly, both $D_{I}$ and $D_{R}$ are decreasing in the current skilled wage rate $w_{t}$ and the next-period skilled wage rate $w_{t+1}$. The domestic skilled-labor market equilibrium obtains if

$$
H_{I, t}+H_{R, t}=H,
$$

\footnotetext{
${ }^{13}$ Even if $\Omega_{L, 0}=\emptyset$ initially, some sector $z$ may be trapped into $\Omega_{L, t}$ in the course of sectoral growth at a certain period $t$ as a result of several unfavorable draws of $\lambda$, implying $\Omega_{L, t} \neq \emptyset$. However, if $\Omega_{L, t}$ becomes large enough, the demand for skilled labor shrinks and, consequently, the skilled wage rate falls. In turn, the threshold value $\phi w_{t}\left(w_{t+1}\right)^{\frac{\alpha}{1-\alpha}} / \lambda_{H}$ between $\Omega_{L, t}$ and $\Omega_{M, t}$ decreases as the skilled wage rate falls. Then, some sectors in $\Omega_{L, t}$ may be back into $\Omega_{M, t}$. It may be the case that $\Omega_{L, t}$ has a certain positive measure in the long run. In this case, we can exclude those (range of) sectors in $\Omega_{L, t}$ from the definition of intermediate good sectors from the very outset.
} 
where $H>0$ is a constant inelastic supply of skilled labor in North. ${ }^{14}$ By taking account of the definitions of $D_{I}$ and $D_{R}$, we can rewrite Eq. (20) as follows:

$$
\frac{\alpha^{\frac{2}{1-\alpha}} \bar{A}_{t} L}{\left(w_{t}\right)^{\frac{1}{1-\alpha}}}+\frac{\beta \bar{A}_{t} L}{\phi w_{t}\left(w_{t+1}\right)^{\frac{\alpha}{1-\alpha}}}=H+\frac{\beta}{\lambda_{H}},
$$

where

$$
\bar{A}_{t} \equiv \int_{0}^{1} A_{t}(z) \mathrm{d} z
$$

denotes the average quality level.

The skilled labor market equilibrium condition, Eq. (20), suggests that there is a potential trade-off between the production of intermediate goods and the R\&D activities. If the economy employs more researchers in any period $t$, then, in that period, the output of the intermediate good has to be reduced. This is also true in the long run, but the reduction in the quantity of intermediate goods will be compensated for by the higher quality of the intermediate goods, which has been realized through R\&D conducted in the previous periods.

\section{Balanced Growth Path}

We define the balanced growth path as a path along which the average quality level $\bar{A}_{t}$ grows at a certain constant rate $g$. We will soon show that, along a balanced growth path, the skilled and unskilled wage rates and the national income grow at a common rate, denoted by $g_{w}$, which is also equal to the growth rate of expenditure, $g_{E}$, as appeared in the Keynes-Ramsey equation (i.e., Eq. (6)). Along a balanced growth path, the (constant) rate of interest induced from Eq. (6) with $\sigma=1$ is $r=\rho+g_{w}$. Then, $\phi$ now becomes

$$
\phi=\left(\rho+1+g_{w}\right) \theta^{-1} .
$$

Clearly, $\phi$ is increasing in $g_{w}$.

\footnotetext{
${ }^{14}$ For the skilled labor in North to be supplied to the Northern skilled labor market, it is necessary that the skilled wage rate $w_{t}$ is not lower than the unskilled wage rate $w_{u, t}$ in North; otherwise the skilled workers in North opt to work as unskilled labor and the skilled labor market collapses. We can ensure that $w_{u, t}<w_{t}$ if the endowment of unskilled labor $L$ is very large relative to the endowment of skilled labor $H$.
} 


\subsection{Growth Rate and the Skilled-Labor Market}

From the skilled labor market equilibrium condition Eq. (21), we recognize that if the average quality level were to grow at a certain constant rate $g$ on the balanced growth path, so must the skilled wage rate. Let $g_{w}$ be the growth rate of the skilled wage rate. Then, if the balanced growth path were to exist, we must have the solutions $\bar{A}_{t}=A(1+g)^{t}$ and $w_{t}=w\left(1+g_{w}\right)^{t}$, where $A$ and $w$ are the initial values of $\bar{A}_{t}$ and $w_{t}$. Substituting these solutions into Eq. (21), we obtain

$$
\frac{A L}{w^{\frac{1}{1-\alpha}}}\left\{\alpha^{\frac{2}{1-\alpha}}+\frac{\beta}{\phi\left(1+g_{w}\right)^{\frac{\alpha}{1-\alpha}}}\right\}\left[\frac{1+g}{\left(1+g_{w}\right)^{\frac{1}{1-\alpha}}}\right]^{t}=H+\frac{\beta}{\lambda_{H}} .
$$

For this condition to hold for all $t$ along the balanced growth path, the term inside the square brackets must be equal to unity, that is,

$$
1+g=\left(1+g_{w}\right)^{\frac{1}{1-\alpha}} .
$$

It is easy to see that, because $0<\alpha<1$, the growth rate of the average quality level $g$ is higher than that of the skilled wage rate $g_{w}$.

Now, the skilled labor market equilibrium condition reduces to

$$
\frac{A L}{w^{\frac{1}{1-\alpha}}}\left[\alpha^{\frac{2}{1-\alpha}}+\frac{\beta}{(1+g)^{\alpha} \phi}\right]=H+\frac{\beta}{\lambda_{H}},
$$

or, equivalently,

$$
w=\left[\left\{\alpha^{\frac{2}{1-\alpha}}+\frac{\beta}{(1+g)^{\alpha} \phi}\right\} \frac{A L \lambda_{H}}{H \lambda_{H}+\beta}\right]^{1-\alpha},
$$

where $\phi=(1+r) \theta^{-1}=\left(1+\rho+g_{w}\right) \theta^{-1}=\left(\rho+[1+g]^{1-\alpha}\right) \theta^{-1} ; \phi$ can be seen as an increasing function of $g$. Eq. (23) describes the relation between the growth rate $g$ and the (initial) skilled wage rate $w$. This relationship is monotone decreasing, which is depicted by curve $S$ in Figure 1 with the slope:

$$
\left.\frac{\mathrm{d} w}{\mathrm{~d} g}\right|_{\text {skilled market }}=\frac{-(1-\alpha) \beta w\left\{(1+g)^{\alpha} \phi_{g}+\alpha(1+g)^{\alpha-1} \phi\right\}}{(1+g)^{\alpha} \phi\left\{\alpha^{\frac{2}{1-\alpha}}(1+g)^{\alpha} \phi+\beta\right\}}<0,
$$

where $\phi_{g}$ denotes the derivative of $\phi$ with respect to $g$. 


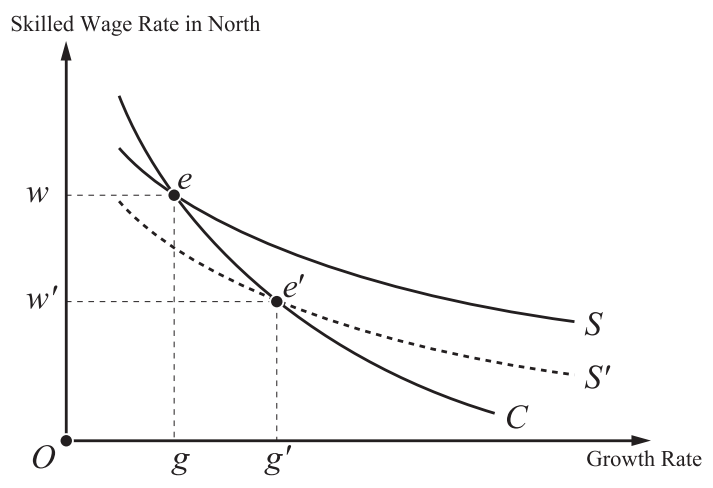

Figure 1: The balanced growth rate and the skilled wage rate in North under communications autarky

The intuition behind the negative relationship between the growth rate $g$ and the (initial) skilled wage rate $w$ can be explained as follows. It should be noted that in our model, the growth of an economy is brought about by both quality improvements through $\mathrm{R} \& \mathrm{D}$ and increases in the skilled labor inputs in the final good production. Suppose that skilled wage rate $w$ decreases. Then, for a given initial quality $A$, a lower skilled wage rate $w$ would reduce the cost of R\&D. More intermediate good firms carry out R\&D, stimulating growth in quality. At the same time, a low skilled wage provides intermediate good firms with more incentives to expand their production, which in turn would increase the output of the final good. Because of these positive effects, the growth rate $g$ increases.

\subsection{Consistency Condition}

The growth rate of the quality in a single sector (say, sector $z$ ) is given by

$$
g_{t}(z) \equiv \lambda h\left(\lambda \mid \widehat{\lambda}_{z, t}\right)
$$


Then, the expected growth rate of quality in sector $z$ in period $t$ becomes

$$
\begin{aligned}
E\left[g_{t}(z)\right] & =E\left[\lambda h\left(\lambda \mid \widehat{\lambda}_{z, t}\right)\right]=\int_{\lambda_{L}}^{\lambda_{H}} \lambda h\left(\lambda \mid \widehat{\lambda}_{z, t}\right) f(\lambda) \mathrm{d} \lambda \\
& =\int_{\widehat{\lambda}_{z, t}}^{\lambda_{H}} \lambda f(\lambda) \mathrm{d} \lambda=\int_{\widehat{\lambda}_{z, t}}^{\lambda_{H}} \frac{\beta}{\lambda} \mathrm{d} \lambda=\beta \ln \left[\frac{\lambda_{H}}{\widehat{\lambda}_{z, t}}\right]
\end{aligned}
$$

Now we impose the following condition: for all $z \in[0,1]$ and for all $t$,

$$
g=E\left[g_{t}(z)\right]
$$

That is, along the balanced growth path, the expected growth rates of the sectors coincides with the actual aggregate growth rate of the overall economy (i.e., the growth rate of the average quality level $\bar{A}_{t}$ ). This can be seen as a consistency condition. The actual (or realized) growth rates of some sectors may be greater and those of others may be smaller than $g$. Even if so, our consistency condition requires that the expected value of the growth rate be consistent with the actual aggregate growth rate. ${ }^{15}$

Combining Eqs. (26) and (27), we have

$$
\exp \left[\frac{g}{\beta}\right]=\frac{\lambda_{H}}{\widehat{\lambda}_{z, t}} .
$$

Expanding $\widehat{\lambda}_{z, t}$ along the balanced growth path where $\left(w_{t}\right)^{\frac{1}{1-\alpha}}$ grows at rate $g$, we have

$$
\phi w^{\frac{1}{1-\alpha}}(1+g)^{\alpha}(1+g)^{t} \exp \left[\frac{g}{\beta}\right]=\lambda_{H} A_{t}(z) L .
$$

Note that the left-hand side of the above equation is independent of $z$. By integrating the above expression over all $z$, we get

$$
\phi w^{\frac{1}{1-\alpha}}(1+g)^{\alpha}(1+g)^{t} \exp \left[\frac{g}{\beta}\right]=\lambda_{H} \bar{A}_{t} L=\lambda_{H} A L(1+g)^{t} .
$$

Finally, we obtain

$$
\phi w^{\frac{1}{1-\alpha}}(1+g)^{\alpha} \exp [g / \beta]=\lambda_{H} A L,
$$

\footnotetext{
${ }^{15}$ One may think of Eq. (27) as a result of the law of large number. Unfortunately, Eq. (27) cannot be derived from the law of large number formally; that is why we simply impose it on our model as an independent condition.
} 
or, equivalently,

$$
w=\left[\frac{A L \lambda_{H}}{(1+g)^{\alpha} \phi \exp [g / \beta]}\right]^{1-\alpha} .
$$

Eq. (28) describes the relation between the growth rate $g$ and the (initial) skilled wage rate $w$ based on the consistency requirement. This is also a monotone decreasing relationship:

$$
\left.\frac{\mathrm{d} w}{\mathrm{~d} g}\right|_{\text {consistency }}=\frac{-(1-\alpha) w\left\{(1+g) \beta \phi_{g}+\alpha \beta \phi+(1+g) \phi\right\}}{(1+g) \beta \phi}<0 .
$$

We depict this relationship by curve $C$ in Figure 1. By comparing Eq. (25) and Eq. (29), we can show that curve $C$ is steeper than curve $S$ :

$$
\left.\frac{\mathrm{d} w}{\mathrm{~d} g}\right|_{\text {consistency }}<\left.\frac{\mathrm{d} w}{\mathrm{~d} g}\right|_{\text {skilled market }}<0 .
$$

Note that the derivation of Eq. (28) is based on the calculation of the expected growth rate of each single intermediate good sector. Unlike Eq. (27), the growth rate $g$ that appears in Eq. (28) only reflects the growth effects of quality improvements through $\mathrm{R} \& \mathrm{D}$, but is separated from the indirect growth effects that come from increased production of the intermediate inputs. Therefore, responding to any given decrease in $w$, the growth rate in Eq. (27) increases more than that in Eq. (28). This explains the differences in the slopes of curve $C$ and curve $S$ in Figure 1.

\subsection{Equilibrium in Communications Autarky}

Combining both Eq. (24) and Eq. (28), we can determine the growth rate and the (initial) skilled wage rate simultaneously and endogenously. Figure 1 illustrates the situation. Curve $S$ represents the skilled labor market equilibrium, Eq. (24), and curve $C$ represents the consistency requirement, Eq. (28). From Eq. (25) and Eq. (29), we know that both curves are downward-sloping and that curve $C$ is "steeper" than curve $S$; accordingly, the intersection of both curves is unique. ${ }^{16}$ At point $e$, where both curves intersect, the growth rate $g$ and the (initial) skilled wage rate $w$ are determined.

\footnotetext{
${ }^{16}$ The proof of the existence of a unique equilibrium is given in Appendix B.
} 
To see the properties of the model, we conduct a comparative statics analysis. Suppose that the supply of the skilled labor $H$ increases. As the right-hand-side (RHS) of Eq. (23) increases, the left-hand-side (LHS) must increase, too. Accordingly, $g$ and/or $w$ have to decrease, implying a downward-shift of curve $S$ to curve $S^{\prime}$ in Figure 1. Point $e^{\prime}$ becomes the new equilibrium point. We state this result more formally in Lemma 1.

Lemma 1. Under communications autarky, there exists a unique growth rate $g>0$ if $H \lambda_{H}>(1+\rho) \alpha /(1-\alpha)$. The growth rate $g$ is increasing in North's endowment of skilled labor, $H$, in the maximal productivity parameter, $\lambda_{H}$, and is decreasing in the rate of impatience, $\rho$; further, it is independent of North's endowment of unskilled labor, $L$.

For the proof, see Appendix B.1.

Notice that whereas the growth rate $g$ increases in response to an increase in $H$, the skilled wage rate must temporarily decrease, as shown in Figure 1. It should be noted that an increase in the skilled labor supply brings about a negative level effect, but it brings about a positive growth effect on the skilled wage rate, because the growth rate of the skilled wage rate $g_{w}$ must increase following the increased growth rate $g$ (as far as we are concerned with the balanced growth path).

With the above results, we can calculate the unskilled wage rate in North in balanced growth. By substituting Eq. (7) and Eq. (11) into Eq. (8) and by taking account of the balanced growth conditions, we obtain

$$
\begin{aligned}
w_{u, t} & =(1-\alpha) L^{-\alpha} \int_{0}^{1}\left[A_{t}(z)\right]^{1-\alpha}\left[\left(\frac{\alpha^{2}}{w_{t}}\right)^{\frac{1}{1-\alpha}} A_{t}(z) L\right]^{\alpha} \mathrm{d} z \\
& =(1-\alpha) \alpha^{\frac{2 \alpha}{1-\alpha}}\left(w_{t}\right)^{\frac{-\alpha}{1-\alpha}} \bar{A}_{t}=w_{u}\left(1+g_{w}\right)^{t},
\end{aligned}
$$

where

$$
w_{u} \equiv(1-\alpha) \alpha^{\frac{2 \alpha}{1-\alpha}} A w^{\frac{-\alpha}{1-\alpha}}
$$

is the initial value of the unskilled wage rate. On one hand, Eq. (30) shows that the unskilled wage rate in North grows at the same rate as the skilled wage rate. On the other hand, Eq. (31) indicates that the initial value of 
unskilled wage rate, $w_{u}$, is negatively related to the initial value of skilled wage rate $w$.

We can also calculate the total (average) profit of the intermediate good firms in balanced growth, which is denoted by $\bar{\pi}_{t}$. From Eq. (12), we obtain

$$
\bar{\pi}_{t} \equiv \int_{0}^{1} \pi_{t}(z) \mathrm{d} z=\theta\left(w_{t}\right)^{\frac{-\alpha}{1-\alpha}} \bar{A}_{t} L=\bar{\pi}\left(1+g_{w}\right)^{t},
$$

where

$$
\bar{\pi} \equiv \theta A L w^{\frac{-\alpha}{1-\alpha}}
$$

is the initial value of the total profit of the intermediate firms. Similar to the unskilled wage rate $\bar{\pi}_{t}$ grows at the rate $g_{w}$, while the initial value $\bar{\pi}$ is negatively related to $w$.

\section{Communications Liberalization}

Now let us consider a situation where skilled labor in South becomes available to the research firms in North due to development of the communications networks such as the Internet - we call this situation "communications liberalization." In South, there is a pool of skilled workers, but no intermediate good sectors nor R\&D firms. ${ }^{17}$ Without communications liberalization, the skilled workers in South cannot bring their ability into full play, instead they work as unskilled labor in a certain traditional sector.

\subsection{R\&D under Communications Liberalization}

Under communications liberalization, each firm $z$ faces several options on how to conduct R\&D. There are four options: (i) do no R\&D project; (ii) do only one R\&D project by hiring only skilled workers in North; (iii) do only

\footnotetext{
${ }^{17}$ In our model, the only motivation of Northern firms for R\&D offshoring is to hire Southern skilled workers via virtual labor mobility by taking advantage of time zone differences. If we consider a different situation where there are some Southern R\&D firms, the possibility of cooperation and competition in R\&D between Northern and Southern R\&D firms may provide those firms with an alternative incentive for R\&D offshoring. For cooperative and non-cooperative incentives for R\&D, see, for example, Marjit (1991) and Kabiraj and Chattopadhyay (2014).
} 
one R\&D project by offshoring its research activities during the nighttimes in North to the skilled workers in South; or (iv) do two consecutive R\&D projects by hiring skilled workers in both North and South and by letting them work day and night continuously. With a slight abuse of notation, let us denote the research firm's strategies that correspond to cases (i), (ii), (iii), and (iv) by $0, R, R^{*}$, and $R R^{*}$, respectively. ${ }^{18}$

Let $\pi_{0}, \pi_{R}, \pi_{R^{*}}$ and $\pi_{R R^{*}}$ be the profits of corresponding strategies, respectively. By definition, we have

$$
\begin{aligned}
\pi_{0} & =\theta\left(w_{t+1}\right)^{\frac{-\alpha}{1-\alpha}} A_{t}(z) L, \\
\pi_{R} & =\theta\left(w_{t+1}\right)^{\frac{-\alpha}{1-\alpha}}(1+\lambda) A_{t}(z) L-\left(1+r_{t}\right) w_{t}, \\
\pi_{R^{*}} & =\theta\left(w_{t+1}\right)^{\frac{-\alpha}{1-\alpha}}(1+\lambda) A_{t}(z) L-\left(1+r_{t}\right) \tau w_{t}^{*}, \\
\pi_{R R^{*}} & =\theta\left(w_{t+1}\right)^{\frac{-\alpha}{1-\alpha}}(1+2 \lambda) A_{t}(z) L-\left(1+r_{t}\right)\left(w_{t}+\tau w_{t}^{*}\right) .
\end{aligned}
$$

Let us assume $\pi_{R}>\pi_{R^{*}}$, which is equivalent to $w_{t}<\tau w_{t}^{*} \cdot{ }^{19}$ This assumption means that if a research firm were to conduct only one $R \& D$ project, it hires only Northern skilled workers. When a research firm conducts two R\&D projects, it offshores part of each project to South even if the Southern skilled wage rate is higher than the Northern skilled wage rate. Because the Southern skilled workers process the assigned part of a project during the nighttime in North (when the Northern skilled workers are sleeping) and vice versa, the Southern and Northern skilled workers can be considered to be "complements" rather than "substitutes." By having two teams of skilled workers (one in North and the other in South) for one project, a research firm can reduce the number of days to complete a project.

If $\pi_{0}<\pi_{R}, \pi_{R R^{*}}$, then a research firm would carry out at least one $\mathrm{R} \& \mathrm{D}$ project. In addition, if $\pi_{R}>\pi_{R R^{*}}$, then the research firm conducts only one (domestic) R\&D project. By the definitions of $\pi$ functions, we can show that $\pi_{0}<\pi_{R}$ if and only if

$$
\lambda>\widehat{\lambda}_{z, t}
$$

\footnotetext{
${ }^{18}$ With the R\&D indicators, strategy 0 corresponds to " $R=R^{*}=0$ " ; strategy $R$ to " $R=1$ and $R^{*}=0 " ; R^{*}$ to " $R=0$ and $R^{*}=1$ "; and $R R^{*}$ to " $R=R^{*}=1$ ".

${ }^{19}$ This assumption of $\pi_{R}>\pi_{R^{*}}$ (equivalently, $w_{t}<\tau w_{t}^{*}$ ) is not essential to our later analysis; it is introduced only for the ease of interpretation. If $\pi_{R}<\pi_{R^{*}}$, we have another case to be examined, but we only obtain essentially the same results.
} 
and $\pi_{R}>\pi_{R R^{*}}$ if and only if

$$
\lambda<\widehat{\lambda}_{z, t}^{*}
$$

where

$$
\widehat{\lambda}_{z, t}^{*} \equiv \frac{\phi\left(\tau w_{t}^{*}\right)\left(w_{t+1}\right)^{\frac{\alpha}{1-\alpha}}}{A_{t}(z) L} .
$$

In what follows, we assume that $w_{t}<\tau w_{t}^{*}$. Then we have

$$
\widehat{\lambda}_{z, t}<\widehat{\lambda}_{z, t}^{*}
$$

With these two threshold values of $\lambda$, the R\&D decision of a research firm on the number of projects can be summarized by the following decision function:

$$
h\left(\lambda \mid \widehat{\lambda}_{z, t}, \widehat{\lambda}_{z, t}^{*}\right)=\left\{\begin{array}{lll}
0 & \text { if } & \lambda<\widehat{\lambda}_{z, t} \\
1 & \text { if } & \widehat{\lambda}_{z, t} \leq \lambda \leq \widehat{\lambda}_{z, t}^{*} \\
2 & \text { if } & \lambda>\widehat{\lambda}_{z, t}^{*}
\end{array}\right.
$$

\subsection{Demand for Research Workers}

The demand function for the domestic research workers in North under communications liberalization is the same as in the case of communications autarky:

$$
D_{R}\left(w_{t}, w_{t+1}\right)=\frac{\beta \bar{A}_{t} L}{\phi w_{t}\left(w_{t+1}\right)^{\frac{\alpha}{1-\alpha}}}-\frac{\beta}{\lambda_{H}} .
$$

To derive the demand function for (foreign) research workers in South, let us consider the probability that a firm $z$ chooses strategy $R^{*}$ (in addition to $R$ ). The probability of $R=R^{*}=1$ becomes $^{20}$

$$
\begin{aligned}
\operatorname{Prob}\left[R=R^{*}=1\right] & =\operatorname{Prob}\left[\lambda>\widehat{\lambda}_{z, t}^{*}\right]=1-\operatorname{Prob}\left[\lambda \leq \widehat{\lambda}_{z, t}^{*}\right] \\
& =1-F\left(\hat{\lambda}_{z, t}^{*}\right) \\
& =\frac{\beta A_{t}(z) L}{\phi\left(\tau w_{t}^{*}\right)\left(w_{t+1}\right)^{\frac{\alpha}{1-\alpha}}}-\frac{\beta}{\lambda_{H}} .
\end{aligned}
$$

\footnotetext{
${ }^{20}$ It should be noted that under our maintained assumption, $\lambda>\widehat{\lambda}_{z, t}^{*}$ implies $\lambda>\widehat{\lambda}_{z, t}$.
} 
By integrating both sides of the above equation over all $z$, we obtain the demand function for Southern research workers:

$$
\begin{aligned}
D_{R^{*}}\left(w_{t}^{*}, w_{t+1}\right) & \equiv \int_{0}^{1}\left[\frac{\beta A_{t}(z) L}{\phi\left(\tau w_{t}^{*}\right)\left(w_{t+1}\right)^{\frac{\alpha}{1-\alpha}}}-\frac{\beta}{\lambda_{H}}\right] \mathrm{d} z \\
& =\frac{\beta \bar{A}_{t} L}{\phi\left(\tau w_{t}^{*}\right)\left(w_{t+1}\right)^{\frac{\alpha}{1-\alpha}}}-\frac{\beta}{\lambda_{H}}
\end{aligned}
$$

This shows that the demand depends negatively on the (current) skilled wage rate in South and the future skilled wage rate in North. ${ }^{21}$

\subsection{Skilled Labor Market in South}

The equilibrium condition for the skilled labor market in North is the same as before; that is, it is described by Eq. (21). Then, let us turn to examine the skilled labor market in South.

In South, there is no other industries nor sectors that can effectively employ the skilled workers. The demand for skilled workers in South only comes from the research firms in North. Let $H^{*}>0$ be the supply of skilled workers in South. Then, the equilibrium condition for the skilled labor market in South becomes ${ }^{22}$

$$
D_{R^{*}}\left(w_{t}^{*}, w_{t+1}\right)=H^{*}
$$

or, equivalently,

$$
\frac{\beta \bar{A}_{t} L}{\phi\left(\tau w_{t}^{*}\right)\left(w_{t+1}\right)^{\frac{\alpha}{1-\alpha}}}=H^{*}+\frac{\beta}{\lambda_{H}} .
$$

From the skilled labor market equilibrium condition in North, we have already shown that if a balanced growth path were to exist, both $\bar{A}_{t}$ and $\left(w_{t}\right)^{\frac{1}{1-\alpha}}$ have to grow at a common rate $g$. Similarly, for Eq. (34) to hold for all $t$ on a balanced growth path under communications liberalization, we

\footnotetext{
${ }^{21}$ Similar to the case of communications autarky, we are assuming here the sets $\Omega_{H, t}$ and $\Omega_{L, t}$ are empty.

${ }^{22} \mathrm{As}$ in the case of skilled labor market in North in communications autarky (see footnote 14), it is necessary that under communications liberalization the Southern skilled wage rate $w_{t}^{*}$ is not less than the Southern unskilled wage rate $w_{u, t}^{*}$. Because, as we will show later, the Southern skilled wage rate is higher than the Southern unskilled wage rate along the balanced growth path, all of $H^{*}$ are employed by Northern firms as skilled workers.
} 
recognize that both $w_{t}^{*}$ and $w_{t+1}$ have to grow at another common rate $g_{w}$. Taking account of the balanced growth condition, we can rewrite Eq. (34) as follows:

$$
\frac{\beta A L}{\phi \tau w^{*} w^{\frac{\alpha}{1-\alpha}}(1+g)^{\alpha}}=H^{*}+\frac{\beta}{\lambda_{H}}
$$

where $w^{*}$ denotes the initial value of the skilled wage rate in South.

\subsection{Consistency Condition under Communications Lib- eralization}

The expected growth rate of sector $z$ is given by

$$
\begin{aligned}
E\left[g_{t}(z)\right] & =\int \lambda h\left(\lambda \mid \widehat{\lambda}_{z, t}, \widehat{\lambda}_{z, t}^{*}\right) f(\lambda) \mathrm{d} \lambda \\
& =\int_{\widehat{\lambda}_{z, t}}^{\widehat{\lambda}_{z, t}^{*}} \lambda f(\lambda) \mathrm{d} \lambda+\int_{\widehat{\lambda}_{z, t}^{*}}^{\lambda_{H}} 2 \lambda f(\lambda) \mathrm{d} \lambda \\
& =\beta \ln \left[\frac{\widehat{\lambda}_{z, t}^{*}}{\widehat{\lambda}_{z, t}}\right]+2 \beta \ln \left[\frac{\lambda_{H}}{\widehat{\lambda}_{z, t}^{*}}\right] \\
& =\beta \ln \left[\frac{\left(\lambda_{H}\right)^{2}}{\widehat{\lambda}_{z, t} \cdot \widehat{\lambda}_{z, t}^{*}}\right] .
\end{aligned}
$$

Similar to the communications autarky case, we impose the following consistency condition: for all $z \in[0,1]$ and for all $t$,

$$
g=E\left[g_{t}(z)\right]
$$

The implication of Eq. (37) is the same as Eq. (27). Combining Eqs. (36) and (37), we have

$$
\exp \left[\frac{g}{\beta}\right]=\frac{\left(\lambda_{H}\right)^{2}}{\widehat{\lambda}_{z, t} \cdot \widehat{\lambda}_{z, t}^{*}} .
$$

By expanding the above expression and by integrating the result over all $z$, we have

$$
\phi\left(\sqrt{\tau w^{*} w}\right) w^{\frac{\alpha}{1-\alpha}}(1+g)^{\alpha}(1+g)^{t} \sqrt{\exp [g / \beta]}=\lambda_{H} \bar{A}_{t} L
$$

Finally, we obtain

$$
\phi\left(\sqrt{\tau w^{*} w}\right) w^{\frac{\alpha}{1-\alpha}}(1+g)^{\alpha} \sqrt{\exp [g / \beta]}=A L \lambda_{H} .
$$




\subsection{Equilibrium under Communications Liberalization}

The skilled labor market equilibrium in North (Eq. (21)), the skilled market equilibrium in South (Eq. (34)), and the consistency condition (Eq. (38)) together describe the equilibrium under communications liberalization. In equilibrium, the skilled wage rate in North $w$, the skilled wage rate in South $w^{*}$, and the growth rate $g$ are determined endogenously.

Combining Eq. (34) and Eq. (38), we can eliminate $w^{*}$ and obtain

$$
w=\left[\frac{A L \lambda_{H}\left\{\left(\lambda_{H} / \beta\right) H^{*}+1\right\}}{\phi(1+g)^{\alpha} \exp [g / \beta]}\right]^{1-\alpha} .
$$

This represents the consistency condition augmented by the skilled labor market equilibrium condition in South. By carefully examining, we recognize that the functional form of Eq. (39) is almost the same as that of the consistency condition Eq. (28) under communications autarky: only difference between them is the term $\left(\lambda_{H} / \beta\right) H^{*}+1$ in the numerator of Eq. (39). If $H^{*}=0$ (i.e., if the Southern skilled workers are not available to the Northern research firms), both consistency conditions coincide. Technically, at least from the viewpoint of North, the communications liberalization can be identified with an increase in $H^{*}$ from $0 .^{23}$

Figure 2 illustrates the effects of communications liberalization on the growth rate and the Northern skilled wage rate. Curve $S$ and curve $C$ represent the skilled labor market equilibrium in North and the consistency condition under communications autarky, respectively. The initial equilibrium under communications autarky is point $e$, where curve $S$ and curve $C$ intersect. Now, let us consider communications liberalization. Communications liberalization does not affect the skilled labor market equilibrium condition in North; therefore, curve $S$ remains unchanged. On the other hand, by communications liberalization, the skilled labor market in South is

\footnotetext{
${ }^{23}$ As illustrated in Figures 1 and 2, an increase in $H$ induces a downward-shift of curve $S$, while an increase in $H^{*}$ induces an upward-shift of curve $C$. Although the effects of increases in $H$ and $H^{*}$ on the growth rate and the skilled wage rate are qualitatively the same, an increase in $H^{*}$ in South cannot be identified with an exogenous increase in $H$ in North. In particular, as we will discuss later, Southern skilled wage rate is different from Northern skilled wage rate.
} 


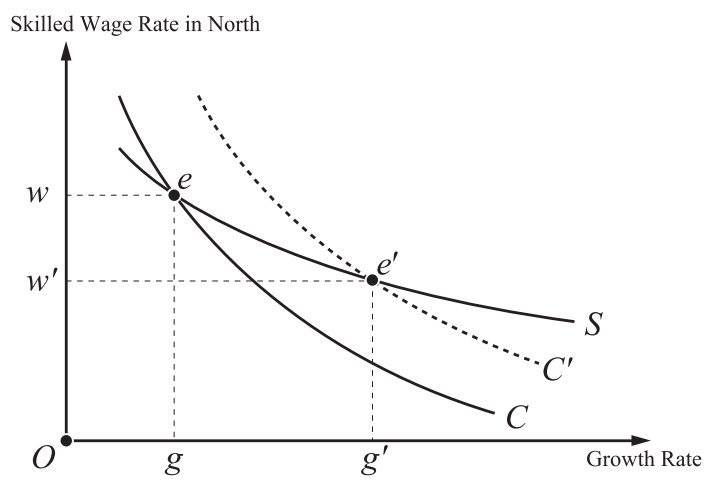

Figure 2: The balanced growth rate and the skilled wage rate in North under communications liberalization

introduced and the consistency condition changes from Eq. (38) to Eq. (39). Accordingly, curve $C$ shifts up as curve $C^{\prime}$ in the figure. The new equilibrium obtains at point $e^{\prime}$. Obviously, the growth rate increases, while the Northern skilled wage rate decreases. We state this result as Proposition 1, a formal proof of which can be found in Appendix B.2.

Proposition 1. Communications liberalization lowers the (initial) skilled wage rate in North, while raises the growth rate.

Similar to Lemma 1, we can show the following corollary.

Corollary 1. Under communications liberalization, the growth rate $g$ is increasing in both North and South endowments of skilled labor, but is independent of both North and South endowments of unskilled labor.

It is well recognized in the context of endogenous growth theory that economic integrations have significant effects on the growth rate of a country or that of the world. The mechanism driving the above result is similar to the scale effect shown by Romer (1990), which says that an increase in the supply of human capital (i.e., skilled workers) brings about an increase in the growth rate. There are, however, some differences between Romer (1990)'s scale effect and our result. In our case of communications liberalization, the additional supply of human capital comes from South located 
in the opposite time zone to North via virtual labor mobility. Further, as explained in Subsection 4.2, the Northern and Southern skilled workers are considered complements for each other. This complementarity between the Southern and Northern skilled workers enables the R\&D production function (Eq. (13)) to work properly. That is, after the communications liberalization, each Northern research firm can employ additional units of Southern skilled workers $R^{*}$ for the production of $\mathrm{R} \& \mathrm{D}$ without affecting the quantity and productivity of the Northern skilled workers $R$. Consequently, the Northern research firms can effectively double the number of R\&D projects and, thereby, increase the growth rate. The virtual labor mobility opens a new channel through which the scale effect spreads across distant countries located in different time zones. ${ }^{24}$

Because of a decrease in the skilled wage rate due to communications liberalization, the intermediate goods become less expensive and will be used more intensively in the production of the Northern final good. Accordingly, the marginal productivity of unskilled labor is increased. Therefore, the Northern unskilled workers now experience not only a hike of the initial unskilled wage rate in the short run, as indicated by Eq. (31), but also an increase in the growth rate in the long run. That is, communications liberalization is inevitably beneficial to the Northern unskilled workers.

On average, a decrease in the skilled wage rate induced by the communications liberalization increases the total gross profit of the intermediate firms and also increases the growth rate of the total profit as shown in Eqs. (32)(33). The situation, however, is different from firm to firm. If an intermediate good firm does not conduct $\mathrm{R} \& \mathrm{D}$, then communications liberalization is beneficial to this firm, because the firm can hire skilled workers by paying a lower

\footnotetext{
${ }^{24}$ Rivera-Batiz and Romer (1991b) have considered an endogenous growth model with two symmetric developed countries and shown that changes in the growth rate (due to trade restrictions) can be decomposed into three different effects: the integration effect, the redundancy effect, and the allocation effect. In our asymmetric North-South trade setting, because the R\&D activities are carried out only in North and the trade pattern of the final goods is assumed a priori, the redundancy and allocation effects have been assumed away at the very outset. Only the integration effect of communications liberalization works in our model and it enables the Northern research firms to enjoy the scale effect of increasingreturns-to-scale in $\mathrm{R} \& \mathrm{D}$ production.
} 
skilled wage rate, but does not incur any $R \& D$ cost. On the other hand, if an intermediate good firm conducts R\&D, it has to incur the R\&D cost, while the benefit from the quality improvement by $R \& D$ will be materialized one period later. Therefore, even though the firm can hire the skilled workers with lower payments and receive a higher gross profit, the net benefit that the firm can receive immediately after the communications liberalization can be negative.

\section{General Equilibrium Consideration}

What will happen to the skilled workers in South under communications liberalization? A superficial observation goes as follows. By eliminating $g$ from Eq. (23) and Eq. (35), we obtain

$$
w^{*}=\frac{H \lambda_{H}+\beta}{\tau\left\{H^{*} \lambda_{H}+\beta\right\}} \cdot w-\frac{A L \alpha^{\frac{2}{1-\alpha}} \lambda_{H}}{\tau\left\{H^{*} \lambda_{H}+\beta\right\}} \cdot w^{\frac{-\alpha}{1-\alpha}},
$$

which indicates a positive relation between $w$ and $w^{*} .{ }^{25}$ With this result, one may conclude that communications liberalization lowers the skilled wage rate $w^{*}$ in South, because communications liberalization induces a decrease in $w$ as shown in Proposition 1. However, this is a false conclusion.

In our setting, because there is no skilled labor market in South before communications liberalization, potential skilled workers in South had to work as unskilled workers in the traditional sector and received the unskilled wage rate in communications autarky. Communications liberalization enables the potential skilled workers in South to work for the research firms in North as the actual skilled workers through the virtual labor mobility. By communications liberalization, the skilled workers in South do not necessarily experience a decrease in the skilled wage rate, but face a switch in the wage rate from unskilled to skilled. In order to answer the aforementioned question appropriately, we have to take explicit account of the endogenous determination of the unskilled wage rate in South and that of the terms of trade between countries in a fully general equilibrium framework.

\footnotetext{
${ }^{25}$ Note that the RHS of Eq. (40) is concave in $w$ and the second term asymptotically approaches zero as $w$ goes infinity.
} 


\subsection{The National Income of North}

Let $I_{t}^{N}$ and $Y_{t}^{N}$ denote the National Income and the Gross Domestic Product (GDP) of North in period $t$, respectively. The GDP of North is defined by the sum of the unskilled wage income, the skilled wage income, and the total profits of the intermediate firms:

$$
Y_{t}^{N} \equiv w_{u, t} L_{u}+w_{t} H+\int_{0}^{1} \pi_{t}(z) \mathrm{d} z
$$

By substituting the equilibrium conditions and the balanced growth conditions, we obtain the following results:

$$
\begin{aligned}
Y_{t}^{N} & =(1-\alpha) \alpha^{\frac{2 \alpha}{1-\alpha}} w^{\frac{-\alpha}{1-\alpha}} A L\left(1+g_{w}\right)^{t}+w\left(1+g_{w}\right)^{t} H+\theta w^{\frac{-\alpha}{1-\alpha}} A L\left(1+g_{w}\right)^{t} \\
& =\left[B L w^{\frac{-\alpha}{1-\alpha}}+w H\right] \cdot\left(1+g_{w}\right)^{t} .
\end{aligned}
$$

where $B \equiv A(1-\alpha)\left\{\alpha^{\frac{2 \alpha}{1-\alpha}}+\alpha^{\frac{1+\alpha}{1-\alpha}}\right\}$. Since all the components of the GDP grow at the same rate as the skilled wage rate $g_{w}$, the GDP itself grows at $g_{w}$ along a balanced growth path.

In communications autarky (i.e., in a situation without R\&D offshoring), the National Income and the GDP coincide with each other. In contrast, under communications liberalization, there is a gap between $I_{t}^{N}$ and $Y_{t}^{N}$, which corresponds to the skilled wage payment by the research firms to the Southern skilled workers.

$$
I_{t}^{N}= \begin{cases}Y_{t}^{N} & (\text { communications autarky }) \\ Y_{t}^{N}-\tau w_{t}^{*} H^{*} & (\text { communications liberalization })\end{cases}
$$

\subsection{The National Income of South}

South specializes in the agricultural good (the South good), which is produced by using unskilled labor with a Ricardian technology. We assume the labor input coefficient is equal to unity. Let $p_{t}$ be the relative price of the South good in terms of the North good in period $t$, which corresponds to the terms of trade (TOT) of South. It should be noted that $p_{t}$ can be identified with the unskilled wage rate in South. Further, let $y_{S}$ and $L^{*}$ be the supply of 
the South good and the endowment of (intrinsic) unskilled workers in South, respectively.

In communications autarky, because the skilled workers have to work as unskilled labor, the total supply of unskilled labor is equal to the sum of the unskilled and skilled workers: $L^{*}+H^{*}$. As we assumed the Ricardian technology with unit labor coefficient, the supply of the South good can be identified with the supply of unskilled labor:

$$
y_{S}=L^{*}+H^{*}
$$

The supply of the South good does not grow over time. The national income $I_{t}^{S}$ of South in communications autarky in period $t$ becomes

$$
I_{t}^{S}=p_{t}\left(L^{*}+H^{*}\right)
$$

As is obvious from Eq. (45), the national income of South, along a balanced growth path, must grow at the same rate as the TOT $p_{t}$.

Under communications liberalization, on the other hand, the skilled workers work for the research firms in North as skilled labor and receive the skilled wage rate $w_{t}^{*}$, and only the (intrinsic) unskilled workers participate in the production of the South good. Accordingly, the supply of the South good and the national income of South under communications liberalization become as follows:

$$
\begin{aligned}
& y_{S}=L^{*}, \\
& I_{t}^{S}=p_{t} L^{*}+w_{t}^{*} H^{*} .
\end{aligned}
$$

One simple fact derived from Eqs. (44) and (46) is that communications liberalization decreases the supply of the South good. The growth of the Southern national income under communications liberalization depends both on the evolution of the TOT and on that of the skilled wage rate in South.

\subsection{Trade in Goods and the Terms of Trade}

As shown in Subsection 3.1, a representative consumer in each country maximizes her temporal utility (Eq. (1)) subject to the temporal budget constraint 
(Eq. (2)). This yields the demand functions for both final goods (Eqs. (3) and (4)). The demand function for the South good becomes as follows: for $k=N, S$,

$$
c_{S, t}^{k}=\frac{\delta E_{t}^{k}}{p_{t}}
$$

where superscript $k(=N$ or $S)$ indicates the identity of each country, $E_{t}^{k}$ is the consumption expenditure, which is determined through the intertemporal utility maximization, and $p_{t}$ is the relative price of the agriculture good (i.e., the TOT of South) in terms of the manufacturing good in period $t$. Under certain conditions, we can show that $E_{t}^{k}$ is equal to the National Income $I_{t}^{k}$ for all $t$ along a balanced growth path.

The demand-supply equation for the South good, $c_{S, t}^{N}+c_{S, t}^{S}=y_{S, t}$, determines the equilibrium TOT $p_{t} \cdot{ }^{26}$ From Eqs. (42) through (48), we can write the trade equilibrium condition in communications autarky as follows:

$$
\frac{\delta}{p_{t}}\left\{Y_{t}^{N}+p_{t}\left(L^{*}+H^{*}\right)\right\}=L^{*}+H^{*} .
$$

By solving it for $p_{t}$, we obtain

$$
p_{t}=\frac{\delta Y_{t}^{N}}{(1-\delta)\left(L^{*}+H^{*}\right)} .
$$

With this result, we can conclude that the equilibrium TOT in communications autarky has to grow at the same rate as $Y_{t}^{N}$ (i.e., $g_{w}$ ) along the balanced growth path. Therefore, for some initial $p$, we must have $p_{t}=p\left(1+g_{w}\right)^{t}$ for all $t$. Substituting this and Eq. (42) into the above result, we obtain

$$
p=\frac{\delta H}{(1-\delta)\left(L^{*}+H^{*}\right)} \cdot w+\frac{\delta B L}{(1-\delta)\left(L^{*}+H^{*}\right)} \cdot w^{\frac{-\alpha}{1-\alpha}}
$$

Eq. (49) indicates the relation between the initial TOT $p$ and the equilibrium skilled wage rate $w$ in North in communications autarky. It should be noted that the RHS of Eq. (49) is convex in $w$ and that the second term asymptotically approaches zero as $w$ goes infinity. This implies that for sufficiently large $w$, the RHS of Eq. (49) can be approximated by the first term, which is linear in $w$.

\footnotetext{
${ }^{26}$ By the Walras law, we can omit the demand-supply equation for the North good.
} 
Let us turn to the case of communications liberalization. From Eqs. (42), (43), (46), (47), and (48), we can write the trade equilibrium condition under communications liberalization as follows:

$$
\frac{\delta}{p_{t}}\left\{Y_{t}^{N}-\tau w_{t}^{*} H^{*}+p_{t} L^{*}+w_{t}^{*} H^{*}\right\}=L^{*} .
$$

By solving it for $p_{t}$, we also obtain

$$
p_{t}=\frac{Y_{t}^{N}-(\tau-1) w_{t}^{*} H^{*}}{(1-\delta) L^{*}} .
$$

Because $Y_{t}^{N}$ and $w_{t}^{*}$ grow at the rate $g_{w}$ along the balanced growth path under communications liberalization, $p_{t}$ has to grow at the same rate $g_{w}$. Similar to the communications autarky case, we obtain

$$
\begin{aligned}
p= & {\left[\frac{\delta H}{(1-\delta) L^{*}}-\frac{\delta(\tau-1) H^{*}\left\{H \lambda_{H}+\beta\right\}}{\tau(1-\delta) L^{*}\left\{H^{*} \lambda_{H}+\beta\right\}}\right] \cdot w } \\
& +\left[\frac{\delta B L}{(1-\delta) L^{*}}+\frac{\delta(\tau-1) A \alpha^{\frac{2}{1-\alpha}} H^{*} \lambda_{H}}{\tau(1-\delta) L^{*}\left\{H^{*} \lambda_{H}+\beta\right\}}\right] \cdot w^{\frac{-\alpha}{1-\alpha}}
\end{aligned}
$$

The RHS of Eq. (50) resembles that of Eq. (49). It is convex in $w$ and the second term also asymptotically approaches zero as $w$ goes infinity.

\subsection{The Skilled Wage Rate in South}

By making use of Eqs. (40), (49), and (50), let us examine the effects of communications liberalization on the TOT (which can be identified with the unskilled wage rate in South) and the skilled wage rate in South.

In Figure 3, the skilled wage rate in North is measured horizontally, and both the TOT and the skilled wage rate in South are measured vertically. Bold curves $W, P$, and $Q$ are the graphs of Eq. (40), Eq. (49), and Eq. (50), respectively. Note that these curves have their respective linear asymptotes, which are represented by three dotted lines originating from point $O$. Here, we are assuming that the slope of the asymptote for curve $W$ is the steepest; that for curve $Q$ is in the middle; and that for curve $P$ is the gentlest: that is,

$$
\frac{\delta H}{(1-\delta)\left(L^{*}+H^{*}\right)}<\frac{\delta H}{(1-\delta) L^{*}}-\frac{\delta(\tau-1) H^{*}\left\{H \lambda_{H}+\beta\right\}}{\tau(1-\delta) L^{*}\left\{H^{*} \lambda_{H}+\beta\right\}}<\frac{H \lambda_{H}+\beta}{\tau\left\{H^{*} \lambda_{H}+\beta\right\}} .
$$




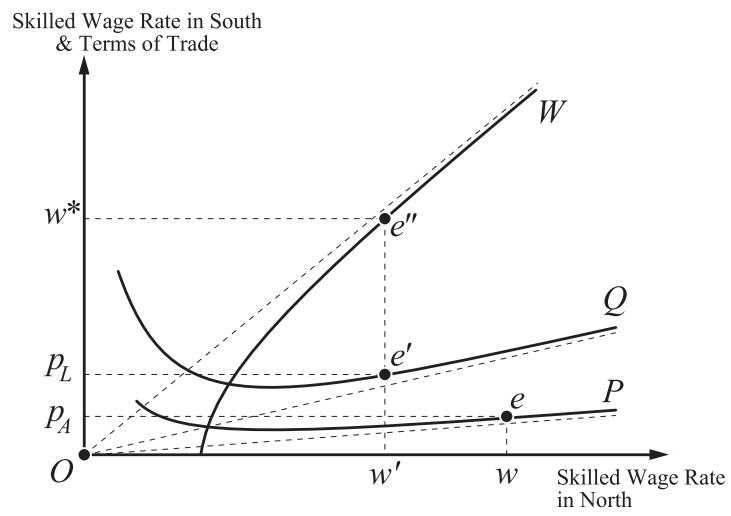

Figure 3: The determination of the terms of trade and the skilled wage rate in South: A case where both types of Southern workers gain.

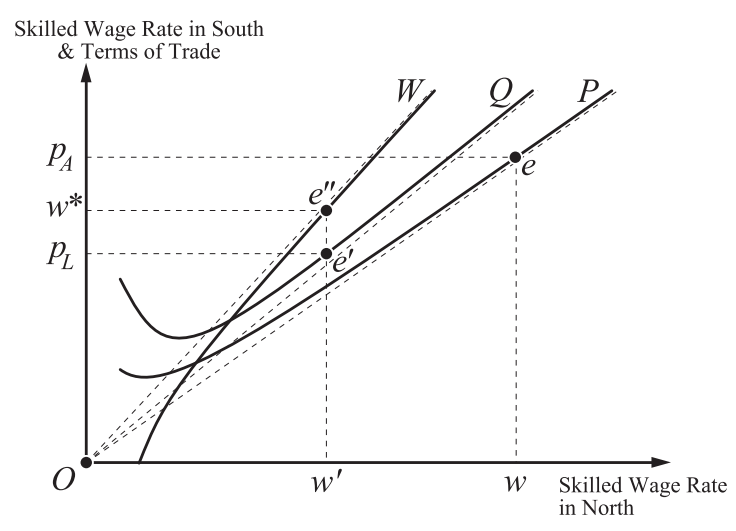

Figure 4: The determination of the terms of trade and the skilled wage rate in South: A case where both types of Southern workers lose.

By inspection, we recognize that the inequalities in Eq. (51) tend to be satisfied if (i) the communication cost is sufficiently small (i.e., $\tau$ is close to unity), (ii) the endowment of the unskilled workers in South (i.e., $L^{*}$ ) is large, (iii) the expenditure share on the South good (i.e., $\delta$ ) is small. ${ }^{27}$

Suppose that the equilibrium skilled wage rate in North in communications autarky is $w$ as in Figure 3. The height of the corresponding point $e$ on curve $P$ stands for the equilibrium TOT in communications autarky. We denote it by $p_{A}$. Now suppose that communications liberalization takes place.

\footnotetext{
${ }^{27}$ In particular, if $\tau=1$, the first inequality is automatically satisfied.
} 
From Proposition 1, we know that the equilibrium skilled wage rate in North decreases down to, say, $w^{\prime}$ as illustrated in the figure. Under communications liberalization, the TOT follows from Eq. (50) and the skilled wage rate in South follows from Eq. (40). Therefore, the equilibrium TOT, denoted by $p_{L}$, and the skilled wage rate in South, denoted by $w^{*}$, under communications liberalization can be found by reading points corresponding to $w^{\prime}$ on curves $Q$ and $W$, respectively. Clearly, we have $p_{L}<w^{*}$. That is, by communications liberalization, the skilled workers in South come to receive a higher wage rate than the unskilled workers in South. Otherwise the skilled workers in South would not work for the Northern research firms; rather they would prefer to working as unskilled workers in the traditional sector in South.

Figure 3 illustrates a case where we have $p_{A}<p_{L}<w^{*}$. The intuition behind this result can be explained as follows. The R\&D offshoring under communications liberalization creates a new market for the skilled labor in South. The Southern skilled workers, who have worked in the traditional sector as unskilled labor, now can move to the R\&D sector in order to earn a higher wage rate and work for the Northern research firms via virtual labor mobility. The labor supply in the traditional sector decreases and, accordingly, the supply of the traditional good (the South good) also decreases. The short supply of the South good induces an increase in the relative price, which corresponds to an increase in the unskilled wage rate in South. In this case, both the skilled and unskilled workers in South can enjoy a positive level effect on their wage rates. Furthermore, because the growth rate also increases, they can enjoy a positive growth effect thereafter. This is in sharp contrast with the case for the skilled workers in North, who suffer from a negative level effect of communications liberalization on the wage rate.

Although it may seem natural that the $R \& D$ offshoring induces an increase in the TOT (i.e., $p_{L}>p_{A}$ ), this is not always the case. Depending on the parameter values, we may have $p_{L}<p_{A}$. On one hand, the R\&D offshoring induces a reduction in the supply of the South good as explained in the previous paragraph. On the other hand, the $R \& D$ offshoring lowers the total income of the Northern skilled workers and, thereby, reduces the demand for the South good. If the demand reduction effect outweighs the 
supply reduction effect, the relative price would fall after communications liberalization. When $p_{L}<p_{A}$, we have two subcases: one where $p_{L}<p_{A}<w^{*}$ and the other $p_{L}<w^{*}<p_{A}$. In the former, the Southern skilled workers gain from communications liberalization, while the Southern unskilled workers do not. In the latter, which is illustrated in Figure 4, both the skilled and unskilled workers in South as well as the skilled workers in North suffer from communications liberalization.

\section{Discussion}

In this section, we discuss some limitations of our model and some possible avenues for extension.

What are the welfare implications of our model? As we assumed in our model that all agents in both countries have the same homothetic temporal utility function (Eq. (1)), we can meaningfully think of the aggregate welfare of each country or that of the world as whole. ${ }^{28}$ Then, we can ask the following legitimate question: How does communications liberalization affect the aggregate welfare of a country or the world, in particular, in the short run? Now, suppose that initially the world is in communications autarky, and there is only trade in the two final goods. Both countries are growing at the same rate. Suppose that suddenly, there is an unexpected advance in communication technology, which allows North to make use of South's skilled workers. There is then a sudden drop in skilled wage in North. In South, skilled workers gain; their real income in terms of the manufacturing good rises as we have shown that $w^{*}>p_{L}$ after communications liberalization. Short-run welfare effects seem ambiguous, because while Northern skilled income falls in the short run, these workers are also shareholders of North's intermediate good firms, and these firms experience an increase in profit due to the lower wage (see Eq. (12)).

Can we say that world's short-run welfare jumps up at the time of communications liberalization? It seems that the result on world short-run welfare

\footnotetext{
${ }^{28} \mathrm{~A}$ concise explanation of the conditions for aggregation of preferences and their relation to the notion of social utility function can be found in Nakanishi (2019, Chapter 4).
} 
could be ambiguous. Just after communications liberalization, the world supply of agriculture good decreases by the amount of $H^{*}$, which by itself induces a decrease in the aggregate world welfare. In contrast, the world supply of manufacturing good increases. ${ }^{29}$ This increase in the manufacturing good, however, may or may not be sufficient to compensate the world welfare loss caused by the decrease in the agriculture good. Of course, in the long run, both countries benefit from communications liberalization, because both countries will get on a new balanced growth path with a higher growth rate. Obviously, the growth effects dominate the costs of short-run loss in wage income.

A limitation of our model is that we have considered only two types of workers, skilled workers and unskilled workers. This is in keeping with most theoretical papers on skilled-unskilled wage differential. However, in reality, there are many skill levels, and the impact of trade liberalization on wages may depend on the level of aggregation of worker types. As documented in Autor and Dorn (2013) the wage profile has experienced substantial changes. Wages of highly skilled workers have risen, and so have wages of very lowskilled workers, whereas the wages of workers in the middle range of skill have declined. While in their paper, Autor and Dorn (2013) attributed these changes to technological changes, in their co-authored works with Hanson (Autor, Dorn, and Hanson, 2013, 2015) they also referred to the impact of trade with China. The offshoring of middle-skilled tasks from North to South might have contributed to the increase in the Northern wages of highly skilled workers, via a possible complementarity between offshored tasks and high-skilled tasks. ${ }^{30}$ On the other hand, middle-skilled labor in South may be near perfect substitutes for middle-skilled labor in North, so that when (cheaper) middle-skilled labor in South can be employed by Northern firms

\footnotetext{
${ }^{29} \mathrm{By}$ simple calculation, we can show that the supply of manufacturing good along a balanced growth path in period $t$ is $y_{N, t}=\alpha^{\frac{-2 \alpha}{1-\alpha}} w^{\frac{-\alpha}{1-\alpha}} A L(1+g)^{(1-\alpha) t}$. Suppose that communications liberalization suddenly occurs in period $t$. Then, the world economy jumps to a new balanced growth path with a higher $g$ and a lower $w$. Consequently, the supply of manufacturing good, $y_{N, t}$, increases along a new balanced growth path in period $t$.

${ }^{30}$ We thank a referee for this insightful suggestion.
} 
(either indirectly, via production of in Southern factories, or directly, via communication network, e.g., labor in computer programming, testing of codes and so on), the wages of middle-skilled labor in North must fall.

We outline below how our model could be extended to account for the Autor-Dorn findings. We can suppose that (i) highly skilled labor can work in research and development or high-end manufacturing, (ii) middle-skilled labor are "grinders" that work in routine manufacturing jobs, and (iii) very low-skilled labor can only work in the low-end of the service industry. If we assume that tasks of middle-skilled labor can be offshored to South where the wage is lower, while North's middle-skilled labor have limited mobility between occupations, then offshoring of these tasks will definitely result in falling relative wages of middle-skilled labor. As for the rising employment and wages in the low-end service sector, that can be explained by a combination of (a) a higher growth rate when economies switch from a low-growth path with communications autarky to a high-growth path thanks to communications liberalization with complementary North and South research teams, and (b) non-homothetic preferences, such that as average income rises, the share of expenditures on service rises (e.g., people go to restaurants or nail saloons more often), a feature that has been incorporated in recent growth models such as Ngai and Pissarides (2007), Kongsamut et al. (2001), and Alvarez-Cuadrado, Long, and Poschke (2018).

Our model abstracts from trade in intermediate goods. Only the final manufacturing good, produced solely in North, and the final agriculture good, produced in solely in South, enter the trade in goods. If we relax this assumption and allow intermediate goods to be traded, some countries that previously do $R \& D$ for quality improvement in their own intermediate goods may drop R\&D altogether if high-quality foreign intermediate goods become importable at reasonable prices. The role of imported intermediate inputs as a replacement of domestic intermediate inputs has been empirically investigated by Li (2019); see also the references in Li (2019). 


\section{Concluding Remarks}

We have shown that communications liberalization can increase the growth rate of both North and South, because it enables the R\&D departments of Northern firms to tap into the pool of South's skilled labor. While the immediate impact effect of the access to South's skilled labor pool on the skilled wage in North is negative, we show that Northern skilled workers benefit in the long run, because the long-run growth rate of their wage is higher under communications liberalization than under communications autarky. Extending the model to account for trade in final goods, we find that South's terms of trade in balanced growth under communications liberalization may improve or worsen, as compared with its terms of trade in balanced growth under communications autarky. But even in the case of a worsening of the terms of trade, the loss that arises from it is likely to be more than compensated for by the the pro-growth effect of communications liberalization.

We also find that, in the short run, a transition from balanced growth under communications autarky to communications liberalization may depress the wage rates of the skilled workers in North and both types of workers in South, while making the owners of monopolistic competition firms better off. This is consistent with the empirical finding that in the past few decades the labor income share has declined in most OECD countries. ${ }^{31}$

\footnotetext{
${ }^{31}$ See, e.g., Alvarez-Cuadrado, Long, and Poschke (2018) and the references cited therein.
} 


\section{Appendix}

\section{A Derivation of the Keynes-Ramsey Equa- tion}

Without loss of generality, we assume that in each country, the population size is unity. In what follows, because the same argument equally applies to both countries, we omit the superscript ( $N$ or $S$ ) that indicates the identity of country. Following Obstfeld and Rogoff (1996), we suppose that a representative consumer holds a stock of net foreign assets, denoted by $B_{t}$, which earns the rate of interest $r_{t}$ (to be determined in equilibrium). The difference between her income, $I_{t}$, and her expenditure, $E_{t}$, is used to buy additional foreign assets. Thus the dynamic equation for $B_{t}$ is

$$
B_{t+1}=\left(1+r_{t}\right) B_{t}+I_{t}-E_{t} .
$$

Using the dynamic programming approach, let $J\left(B_{t}\right)$ denote the value function of the consumer's intertemporal optimization problem. The Bellman equation is

$$
\mathcal{E}_{t-1} J\left(B_{t}\right)=\max _{E_{t}}\left[V\left(E_{t}, p_{t}\right)+\frac{1}{1+\rho} \mathcal{E}_{t}\left(J\left(B_{t+1}\right)\right)\right]
$$

where $\mathcal{E}_{t}$ is the expectation operator, $B_{t+1}$ is as given by Eq. (52) and $\rho>0$ is the consumer's degree of impatience. ${ }^{32}$ At the beginning of period $t$, the consumer, facing the given market rate of interest $r_{t}$, makes a decision on her consumption expenditure $E_{t}$. The optimal decision must maximize the RHS of Eq. (53). We obtain the FOC:

$$
(1+\rho) \frac{\partial V\left(E_{t}, p_{t}\right)}{\partial E_{t}}-\mathcal{E}_{t}\left[J^{\prime}\left(B_{t+1}\right)\right]=0
$$

Applying the Envelope theorem, Eq. (53) yields

$$
\mathcal{E}_{t-1} J^{\prime}\left(B_{t}\right)=\frac{\left(1+r_{t}\right)}{1+\rho} \mathcal{E}_{t}\left[J^{\prime}\left(B_{t+1}\right)\right]
$$

\footnotetext{
${ }^{32}$ For the dynamic programming approach and the Bellman equation, see Stokey and Lucas (1989).
} 
Using Eqs. (54) and (55), we get

$$
(1+\rho) \frac{\partial V\left(E_{t-1}, p_{t-1}\right)}{\partial E_{t-1}}=\left(1+r_{t}\right) \frac{\partial V\left(E_{t}, p_{t}\right)}{\partial E_{t}}
$$

Applying the logarithmic operator, we get the Euler's equation:

$$
\ln \left[\frac{\partial V\left(E_{t-1}, p_{t-1}\right)}{\partial E_{t-1}}\right]-\ln \left[\frac{\partial V\left(E_{t}, p_{t}\right)}{\partial E_{t}}\right]=\ln \left[1+r_{t}\right]-\ln [1+\rho] .
$$

Applying the linear approximation to the above Euler's equation, we get the following results consecutively: ${ }^{33}$

$$
\begin{aligned}
r_{t}-\rho & =-\left[\frac{V_{E_{t}}-V_{E_{t-1}}}{V_{E_{t}}}\right] \\
& =-\left[\frac{V_{E E} \times \Delta E_{t}+V_{E p} \times \Delta p_{t}}{V_{E}}\right] \\
& =-\left[\frac{E \times V_{E E}}{V_{E}}\right]\left[\frac{\Delta E_{t}}{E_{t}}\right]-\left[\frac{p \times V_{E p}}{V_{E}}\right]\left[\frac{\Delta p_{t}}{p_{t}}\right] .
\end{aligned}
$$

This is the Keynes-Ramsey equation, which relates the rate of interest $r_{t}$ to (i) the growth rate of consumption $\left[\frac{\Delta E_{t}}{E_{t}}\right]$, multiplied by $1 / \sigma$, where $\sigma$ is the elasticity of intertemporal substitution, $\sigma \equiv-\left[\frac{V_{E}}{E \times V_{E E}}\right]>0$ and (ii) the growth rate of the terms of trade, $\left[\frac{\Delta p_{t}}{p_{t}}\right]$, multiplied by the price elasticity of marginal indirect utility of expenditure. The indirect utility function derived in Eq. (5) implies that the price elasticity of marginal indirect utility of expenditure is identically zero. Thus the Keynes-Ramsey rule reduces to the usual textbook formula:

$$
r_{t}=\rho+\frac{1}{\sigma}\left[\frac{\Delta E_{t}}{E_{t}}\right]
$$

Under balanced growth, the growth rate of expenditure is equal to the growth rate of income, which is the same for both North and South as we have shown in the main text:

$$
\left[\frac{\Delta E_{t}}{E_{t}}\right]=\left[\frac{\Delta I_{t}}{I_{t}}\right] \equiv g_{w} .
$$

\footnotetext{
${ }^{33}$ The expressions $V_{E}$ and $V_{E E}$ represent the first-order and second-order derivatives of $V$ with respect to $E$. Similarly, $V_{E p}$ represents the second-order cross derivative of $V$ with respect to $E$ and $p$.
} 
Thus, along the balanced growth path, we have

$$
r=\rho+\frac{g_{w}}{\sigma}
$$

where $\sigma=1$ because of the the indirect utility function that we derived in Eq. (5).

\section{B Existence of a Unique Equilibrium}

\section{B.1 Communications Autarky}

We show the proof of the existence of a unique equilibrium of the balanced growth path and the skilled wage rate under communications autarky.

From Eq. (24) and Eq. (28), we have both

$$
\frac{A L}{w^{\frac{1}{1-\alpha}}}\left[\alpha^{\frac{2}{1-\alpha}}+\frac{\beta}{\phi(1+g)^{\alpha}}\right]=H+\frac{\beta}{\lambda_{H}}
$$

and

$$
\phi(1+g)^{\alpha} \exp \left[\frac{g}{\beta}\right]=\lambda_{H} \frac{A L}{w^{\frac{1}{1-\alpha}}} .
$$

By eliminating $A L / w^{\frac{1}{1-\alpha}}$ from the above expressions, we obtain

$$
\left[\phi(1+g)^{\alpha} \alpha^{\frac{2}{1-\alpha}}+\beta\right] \exp \left[\frac{g}{\beta}\right]=H \lambda_{H}+\beta
$$

where $\phi=\left(\rho+[1+g]^{1-\alpha}\right) \theta^{-1}$. The RHS is a constant (with respect to $g$ ) and the LHS of the above expression is a function $\psi(g)$, which is monotonically increasing in $g$, with

$$
\psi(0)=(1+\rho) \alpha /(1-\alpha)+\beta \quad \text { and } \quad \lim _{g \rightarrow+\infty} \psi(g)=+\infty .
$$

Therefore, if

$$
H \lambda_{H}>(1+\rho) \alpha /(1-\alpha),
$$

we have a unique positive balanced growth rate that solves Eq. (56). From the above argument, it is easy to see that the unique growth rate becomes higher if the LHS of Eq. (57) is larger or if the RHS is smaller. Further, because Eq. (56) is independent of the unskilled labor endowment $L$, so is the equilibrium growth rate $g$. This proves Lemma 1 . 


\section{B.2 Communications Liberalization}

Let us turn to the existence of a unique equilibrium of the balanced growth path and the skilled wage rate under communications liberalization.

By squaring both sides of Eq. (38), we get

$$
\begin{aligned}
\phi^{2} \tau w^{*} w\left\{w^{\frac{\alpha}{1-\alpha}}(1+g)^{\alpha}\right\}^{2} \exp [g / \beta] & =\left(A L \lambda_{H}\right)^{2} \\
\left\{\phi \tau w^{*} w^{\frac{\alpha}{1-\alpha}}(1+g)^{\alpha}\right\} \phi w^{\frac{1}{1-\alpha}}(1+g)^{\alpha} \exp [g / \beta] & =\left(A L \lambda_{H}\right)^{2} .
\end{aligned}
$$

Thus

$$
\frac{\phi w^{\frac{1}{1-\alpha}}(1+g)^{\alpha} \exp [g / \beta]}{A L \lambda_{H}}=\frac{A L \lambda_{H}}{\phi \tau w^{*} w^{\frac{\alpha}{1-\alpha}}(1+g)^{\alpha}} .
$$

On the other hand, from Eq. (34), we obtain

$$
\frac{A \lambda_{H}}{\phi \tau w^{*} w^{\frac{\alpha}{1-\alpha}}(1+g)^{\alpha}}=\frac{H^{*} \lambda_{H}+\beta}{\beta} .
$$

Combining these two results, we obtain

$$
\begin{aligned}
\frac{\phi w^{\frac{1}{1-\alpha}}(1+g)^{\alpha} \exp [g / \beta]}{A L \lambda_{H}} & =\frac{H^{*} \lambda_{H}+\beta}{\beta} \\
\frac{\beta \phi w^{\frac{1}{1-\alpha}}(1+g)^{\alpha} \exp [g / \beta]}{A L \lambda_{H}} & =H^{*} \lambda_{H}+\beta .
\end{aligned}
$$

Therefore,

$$
\frac{A L \lambda_{H}}{w^{\frac{1}{1-\alpha}}}=\frac{\beta \phi(1+g)^{\alpha} \exp [g / \beta]}{H^{*} \lambda_{H}+\beta} .
$$

Furthermore, from Eq. (21), we have

$$
\left[\alpha^{\frac{2}{1-\alpha}}+\frac{\beta}{\phi(1+g)^{\alpha}}\right] \frac{A L \lambda_{H}}{w^{\frac{1}{1-\alpha}}}=H \lambda_{H}+\beta .
$$

By eliminating the term $A L \lambda_{H} / w^{\frac{1}{1-\alpha}}$ from Eq. (58) and Eq. (59), we finally obtain

$$
\beta\left\{\phi(1+g)^{\alpha} \alpha^{\frac{2}{1-\alpha}}+\beta\right\} \exp [g / \beta]=\left(H \lambda_{H}+\beta\right)\left(H^{*} \lambda_{H}+\beta\right),
$$

where $\phi=\left(\rho+[1+g]^{1-\alpha}\right) \theta^{-1}$. The RHS is a constant (with respect to $g$ ) and the LHS is a monotonically increasing function $\beta \psi(g)$ of $g$, which is equal to the LHS of Eq. (56) multiplied by $\beta$, with the properties that

$$
\beta \psi(0)=\beta[(1+\rho) \alpha /(1-\alpha)+\beta]>0 \text { and } \lim _{g \rightarrow+\infty} \beta \psi(g)=+\infty .
$$


Therefore, if

$$
\beta\{(1+\rho) \alpha /(1-\alpha)+\beta\}<\left(H \lambda_{H}+\beta\right)\left(H^{*} \lambda_{H}+\beta\right),
$$

there exists a unique positive balanced growth rate under communications liberalization. Note that if $H^{*}=0$ (which corresponds to communications autarky), the condition Eq. (61) reduces to Eq. (57).

Now we prove Proposition 1. Let $g^{a}$ be the solution to Eq. (56) and $g^{\ell}$ be the solution to Eq. (60). We have to show $g^{a}<g^{\ell}$. Dividing both sides of Eq. (60) by $\beta$, we obtain

$$
\psi(g)=\left(H \lambda_{H}+\beta\right)\left[\frac{H^{*} \lambda_{H}}{\beta}+1\right] .
$$

The LHS of the above equation is the same as Eq. (56) and the RHS is greater than $H \lambda_{H}+\beta$ (i.e., greater than the RHS of Eq. (56)). Since $\psi$ is monotonically increasing in $g$, then we obtain $g^{a}<g^{\ell}$. Corollary 1 follows from the facts that Eq. (60) is independent of both $L$ and $L^{*}$ and, that the RHS of Eq. (62) is monotonically increasing in both $H$ and $H^{*}$. 


\section{References}

Acemoglu, D., and Autor, D. (2011). Skills, tasks and technologies: Implications for employment and earnings. in: O. Ashenfelter and D.E. Card (eds.), Handbook of Labor Economics, Volume 4., Elsevier, Amsterdam.

Acemoglu, D., Autor, D., Dorn, D., and Hanson, G. (2015). Import competition and the great U.S. employment sag of the 2000s. CESifo Working Paper No. 5366.

Aghion, P., and Howitt, P. (1992). A model of growth through creative destruction. Econometrica 60 (2): 323-351.

Aghion, P., and Howitt, P. (2009). The Economics of Growth. The MIT Press, Cambridge, Massachusetts.

Alvarez-Cuadrado, F., Long, N.V., and Poschke, M. (2018). Capital labor substitution, structural change and the labor income share. Journal of Economic Dynamics and Control, Vol. 87 (C): 206-231.

Autor, D.H. and Dorn, D. (2013). The growth of low-skill service jobs and the polarization of the US labor market. American Economic Review 103 (5): 1553-1597.

Autor, D., Dorn, D., and Hanson, G. (2013). The China syndrome: Local labor market effects of import competition in the United States. American Economic Review 103 (6): 2121-2168.

Autor, D., Dorn, D., and Hanson, G. (2015). Untangling trade and technology: Evidence from local labor markets. Economic Journal 125: 621-646.

Barro, R.J. (1974). Are government bonds net wealth? Journal of Political Economy 82 (6): 1095-1117

Bertrand, O., and Mol, M.J. (2013). The antecedents and innovation effects of domestic and offshore R\&D outsourcing: The contingent impact of cognitive distance and absorptive capacity. Strategic Management Journal 34: $751-760$. 
Blinder, A.S. (2006). Offshoring: The next industrial revolution?. Foreign Affairs, March/April 2006: 113-128.

Blinder, A.S. (2009). How many US jobs might be offshorable?. World Economics 10 (2): 41-78.

Branstetter, L.G., Glennon, B.M., and Jensen, J.B. (2018). The IT revolution and the globalization of R\&D. NBER Working Paper Series 24707, National Bureau of Economic Research.

Brown, C., and Linden, G. (2009). Chips and Change: How Crisis Reshapes the Semiconductor Industry. Cambridge, MA: MIT Press.

Cairncross, F. (1997). The Death of Distance. Boston, MA: Harvard Business School Press.

Castellani, D., and Pieri, F. (2013). R\&D offshoring and the productivity growth of European regions. Research Policy 42: 1581-1594.

D'Agostino, L.M., Laursen, K., and Santangelo, G.D. (2013). The impact of R\&D offshoring on the home knowledge production of OECD investing regions. Journal of Economic Geography 13: 145-175.

Davis, C., and Hashimoto, K. (2018). Innovation and manufacturing offshoring with fully endogenous productivity growth. unpublished manuscript.

Ernst, D. (2006). Innovation Offshoring: Asia's Emerging Role in Global Innovation Networks. Honolulu, Hawai: East-West Center.

Gersbach, H., Schneider, M., and Schneller, O. (2013). Basic research, openness and convergence. Journal of Economic Growth 18 (1): 33-68.

Grossman, G.M. and Rossi-Hansberg, E. (2008). Trade in tasks: A simple theory of offshoring, American Economic Review 98:1978-97.

Gupta, A., and Seshasai, S. (2007). 24-Hour knowledge factory: Using internet technology to leverage spatial and temporal separations. ACM Transactions on Internet Technology 7 (3), Article 14. 
Kabiraj, T., and Chattopadhyay, S. (2014). Cooperative vs. noncooperative R\&D incentives under incomplete information. MPRA (Munich Personal RePEc Archive) Paper No. 59259. https://mpra.ub.unimuenchen.de/59259.

Kikuchi, T. (2006). Time zones, outsourcing and patterns of international trade. Economics Bulletin 6 (15): 1-10.

Kikuchi, T. (2009). Time zones as a source of comparative advantage. Review of International Economics 17 (5): 961-967.

Kikuchi, T., and Iwasa, K. (2010). A simple model of service trade with time zone differences. International Review of Economics and Finance 19: $75-80$.

Kikuchi, T., and Long, N.V. (2011). Shift working and trade in labor services with time zone differences. Pacific Economic Review 16 (5): 553-564.

Kikuchi, T., and Marjit, S. (2011). Growth with time zone differences. Economic Modelling 28: 637-640.

Kongsamut, P., Rebelo, S., Xie, D. (2001). Beyond balanced growth. Review of Economic Studies 68: 869-882.

Krugman, P. (2008). Trade and wages, reconsidered. Brookings Papers on Economic Activity, Spring 2008: 103-138.

Li, Y. (2019). Three essays on the impact of trade liberalization on firms' behavior and performance. Doctoral Dissertation, McGill University.

Macher, J.T. and Mowery, D.C. (eds.). (2008). Innovation in Global Industries: US Firms Competing in a New World (Collected Studies). Washington, DC: National Academies Press.

Marjit, S. (1991). Incentives for cooperative and non-cooperative R and D in duopoly. Economics Letters 37: 187-191. 
Marjit, S. (2007). Trade theory and the role of time zones. International Review of Economics and Finance 16: 153-160.

Marjit, S., and Mandal, B. (2017). Virtual trade between separated time zones and growth. International Journal of Economic Theory 13: 171183.

Matsuoka, Y., and Fukushima, M. (2010). Time zones, shift working and international outsourcing. International Review of Economics and Finance 19: $769-78$.

Naghavi, A. and Ottaviano, G. (2009). Offshoring and product innovation. Economic Theory 38: 517-532.

Nakanishi, N. (2019). The Essence of International Trade Theory. World Scientific, Singapore.

Nakanishi, N., and Long, N.V. (2015). The distributional and allocative impacts of virtual labor mobility across time zones through communication networks. Review of International Economics 23 (3): 638-662.

Ngai, L.R. and Pissarides, C. (2007). Structural change in a multisector model of growth. American Economic Review 97 (1): 429-443.

Nieto, M.J., and Rodriguez, A. (2011). Offshoring of R\&D: Looking abroad to improve innovation performance. Journal of International Business Studies 42: 345-361.

Obstfeld, M. and Rogoff, K. (1996), Foundations of International Macroeconomics, MIT Press.

Rivera-Batiz, L.A., and Romer, P.M. (1991a). Economic integration and endogenous growth. The Quarterly Journal of Economics 106 (2): 531-555.

Rivera-Batiz, L.A., and Romer, P.M. (1991b). International trade with endogenous technological change. European Economic Review 35: 971-1004. 
Rodriguez-Clare, A. (2010). Offshoring in a Ricardian world. American Economic Journal: Macroeconomics 2: 227-258.

Rodriguez, A., and Nieto, M.J. (2016). Does R\&D offshoring lead to SME growth? Different governance modes and the mediating role of innovation. Strategic Management Journal 37: 1734-1753.

Romer, P.M. (1990). Endogenous technological change. Journal of Political Economy 98 (5): 71-102.

Stokey, N.L. and Lucas, R.E. (1989), Recursive Methods in Economic Dynamics, Harvard University Press, Cambridge, Mass.

Wachter, R.M. (2006). The dis-location of U.S. medecine-The implications of medical outsourcing. The New England Journal of Medicine 7: 661-665. 